\title{
Heme Oxygenase-1 Is a Pivotal Modulator of Bone Turnover and Remodeling: Molecular Implications for Prostate Cancer Bone Metastasis
}

\author{
Nicolás Anselmino, ${ }^{1,2}$ Michael Starbuck, ${ }^{3}$ Estefania Labanca, ${ }^{3}$ Javier Cotignola, ${ }^{1,2}$ Nora Navone, ${ }^{3}$ \\ Geraldine Gueron, ${ }^{1,2}$ Ana C. Zenclussen, ${ }^{4}$ and Elba Vazquez ${ }^{1,2}$
}

\begin{abstract}
Aims: Bone is the most frequent site of prostate cancer (PCa) metastasis. Tumor cells interact with the bone microenvironment interrupting tissue balance. Heme oxygenase-1 (HO-1; encoded by Hmoxl) appears as a potential target in PCa maintaining the cellular homeostasis. Our hypothesis is that HO-1 is implicated in bone physiology and modulates the communication with PCa cells. Here we aimed at (i) assessing the physiological impact of Hmoxl gene knockout (KO) on bone metabolism in vivo and (ii) determining the alterations of the transcriptional landscape associated with tumorigenesis and bone remodeling in cells growing in coculture (PCa cells with primary mouse osteoblasts [PMOs] from BALB/c Hmoxl ${ }^{+++}, \mathrm{Hmoxl}^{+/-}$, and Hmox $1^{-/-}$mice).

Results: Histomorphometric analysis of $\mathrm{Hmoxl}^{-/-}$mice bones exhibited significantly decreased bone density with reduced remodeling parameters. A positive correlation between Hmoxl expression and Runx2, Collal, Csfl, and Opg genes was observed in PMOs. Flow cytometry studies revealed two populations of PMOs with different reactive oxygen species (ROS) levels. The high ROS population was increased in PMOs Hmoxl ${ }^{+/-}$ compared with $H$ moxl $I^{+/+}$, but was significantly reduced in PMOs $H m o x I^{-/}$, suggesting restrained ROS tolerance in KO cells. Gene expression was altered in PMOs upon coculture with PCa cells, showing a pro-osteoclastic profile. Moreover, HO-1 induction in PCa cells growing in coculture with PMOs resulted in a significant modulation of key bone markers such as $P T H r P$ and $O P G$.

Innovation and Conclusion: We here demonstrate the direct implications of HO-1 expression in bone remodeling and how it participates in the alterations in the communication between bone and prostate tumor cells. Antioxid. Redox Signal. 32, 1243-1258.
\end{abstract}

Keywords: $H M O X 1$, bone remodeling, prostate cancer, osteoblasts, osteoclasts

\footnotetext{
${ }^{1}$ Laboratorio de inflamación y Cáncer, Departamento de Química Biológica, Facultad de Ciencias Exactas y Naturales, Universidad de Buenos Aires, Buenos Aires, Argentina.

${ }^{2}$ Instituto de Química Biológica de la Facultad de Ciencias Exactas y Naturales (IQUIBICEN), CONICET-Universidad de Buenos Aires, Buenos Aires, Argentina.

${ }^{3}$ Department of Genitourinary Medical Oncology, The University of Texas MD Anderson Cancer Center, Houston, Texas, USA.

${ }^{4}$ Experimental Obstetrics and Gynecology, Medical Faculty, Otto-von-Guericke University Magdeburg, Magdeburg, Germany.

Part of the abstract of this work was published in Medicina 78(Suppl III): 51, 2018.
} 


\section{Innovation}

Advanced prostate cancer exhibits bone dissemination as the preferable site for metastasis accompanied by an average survival of $\sim 40$ months. Bone metastases are incurable and only palliative treatments are available. Our results showcase for the first time the direct effect of the heme oxygenase-1 gene (Hmoxl gene) on bone turnover and remodeling and demonstrate that its modulation on both prostate tumor cells and bone cells changes their communication altering the tumoral bone niche. A better understanding of how these processes influence the early onset of bone metastasis can shed light into more tailored therapies.

\section{Introduction}

$\mathbf{P}$ ROSTATE CANCER (PCa) is the second-most frequently diagnosed cancer and the fifth leading cause of cancerrelated deaths in men worldwide (5a). PCa progression is dominated by a constant tumor adaptation $(32,40)$. The acquisition of resistance to androgen deprivation therapy coincides with PCa bone metastases in most cases, indicating the presence of a bone/epithelial interaction that drives organ-specific progression. Bidirectional interaction between bone cells and PCa cells suggests that not only growth factors derived from the tumor can affect bone cells but also that cells from the bone microenvironment stimulate metastatic tumor growth $(32,37,62)$.

Bone is a mineralized connective tissue that has four main cell types: osteoblasts, bone "lining" cells, osteocytes, and osteoclasts (14). This tissue has important functions such as locomotion, support and protection of soft tissues, calcium and phosphate reservoir, and bone marrow shelter $(12,52)$. Bone is a highly dynamic organ that is continuously degraded by osteoclasts and regenerated by osteoblasts $(5,9,33,56)$.

Osteoblasts are responsible for bone formation, synthesizing and secreting proteins to form the osteoid, which will then be mineralized and converted to mature bone (11). These cells derive from mesenchymal stem cells (MSCs), which can also be differentiated to other cell types, including adipocytes and chondrocytes (51). The commitment of MSCs toward a lineage of bone progenitor cells requires the expression of specific genes, followed by temporarily programmed steps that include the synthesis of bone morphogenetic proteins (BMPs) and members of the Wnt pathway (18). The expression of Runtrelated transcription factor 2 (Runx2), Dlx5, and Osx is crucial for osteoblast differentiation $(7,64)$.

Osteoclasts are differentiated multinucleated cells that originate from mononuclear cells of hematopoietic stem cell lineage, under the influence of several factors (25). These factors include the macrophage colony stimulating factor (M-CSF or CSF-1), secreted by bone progenitor mesenchymal cells and osteoblasts, and RANKL (receptor activator for nuclear factor $\kappa$ B ligand), secreted by osteoblasts, osteocytes, and stromal cells (42). The RANKL/RANK (receptor activator for nuclear factor $\kappa \mathrm{B}$ )/OPG (osteoprotegerin) axis is the main mediator of osteoclastogenesis (49).

The bone remodeling process is a highly complex cycle that is carried out by the concerted action of the cell types described above (52). Systemic factors for bone homeostasis maintenance include parathyroid hormone (PTH), calcitonin, 1,25-dihydroxy vitamin D3 (calcitriol), glucocorticoids, androgens, and estrogens $(6,36,59,70)$. PTH-related protein (PTHrP), which also binds to the PTH receptor, has been reported to influence bone remodeling (6).

PCa cell bone affinity may owe to the expression of genes that predispose cells to lodge in the bone marrow, although it is also possible that these cells acquire osteomimetic properties after being located within the bone compartment. Once in the bone, disseminated tumor cells or their progeny may have osteoblastic, osteoclastic, or both effects $(13,54)$. Metastatic tumor cells are not the only ones responsible for inducing bone destruction/formation. This process mainly involves osteoblasts and osteoclasts. PTHrP, interleukin (IL)-1, IL-6, and prostaglandin E2 (PGE2) can regulate the osteoblast production of RANKL/OPG and modulate osteoclast activation (44).

The concept that there are basically two types of bone metastases_osteoblastic or osteoclastic_-might be too simplistic. The processes of resorption and bone formation are usually linked or coupled. There is plenty of evidence that both processes are activated in the majority of bone metastases (44).

Reactive oxygen species (ROS) can cause severe tissue damage due to the accumulation of changes in vital macromolecules. Currently, the mechanisms by which cells sense pro-oxidant states and activate signaling pathways to counteract changes are not completely known. However, the expression of heme oxygenase (HO) family enzymes (heme catabolizers) is a well-preserved strategy throughout evolution to counteract ROS (39).

$\mathrm{HO}-1$ is a $32 \mathrm{kDa}$ protein inducible through a variety of stimuli, including ROS and inflammatory cytokines (46). It is well known that inflammation favors $\mathrm{PCa}$ and its progression (41). Proinflammatory factors secreted by PCa and bone cells and the subsequent release of bone matrix factors mediate the paracrine/autocrine interaction between $\mathrm{PCa}$ cells, osteoblasts, and osteoclasts, ultimately determining the bone phenotype and PCa progression $(15,22)$. Oxidative stress is a natural consequence of the inflammatory process and acts as a modulator for the mineralized tissue function (63).

We previously demonstrated that $\mathrm{HO}-1$ participates in $\mathrm{PCa}$ bone metastasis, restoring osteoblast proliferation (16), which was shown to be significantly inhibited by coculturing PC3 cells with primary mouse osteoblasts (PMOs) (67). We also found that $\mathrm{HO}-1$ is capable of modulating signaling pathways relevant to bone metastasis, such as $\mathrm{FoxO} / \beta$-catenin, and promotes bone remodeling when tumor cells are transplanted into the femur of SCID mice (16). More recently, we reported that HO-1 modulates cellular adhesions in $\mathrm{PCa}$, increasing E-cadherin and $\beta$-catenin levels and its subsequent relocation to the plasma membrane, favoring a more epithelial phenotype (21).

We also reported that $\mathrm{HO}-1$ induction alters the expression of different cytoskeletal genes and is associated with key factors that induce the remodeling of actin filaments in the filopodia, increasing adhesion and decreasing PCa cell invasiveness (48). However, the effect of HO-1 deficiency in the bone physiology and in the communication between $\mathrm{PCa}$ cells and cells of the bone stroma is yet to be fully explored.

Here, we thoroughly describe the direct effect of heme oxygenase-1 gene (Hmoxl) total, partial, or absent expression in impairing bone turnover and remodeling. We further 
established coculture system models of human PCa cells with PMOs from Hmoxl transgenic mice, and delineated a set of osteoblastic and osteolytic genes (PTHrP, OPG, and $R A N K L$ ) and analyzed how HO-1 expression levels affected this signature.

\section{Results}

Morphological, genetic, and physiological characterization of bone from knockout $\mathrm{Hmox} 1$ mice

We have previously used a coculture system of PC 3 cells with PMOs to show that the decrease in PMO proliferation induced by tumor cells was restored when these cells were treated with hemin, a specific pharmacological inducer of HO-1. Hemin treatment increased the expression of DKK1 (inhibitor of $\mathrm{Wnt} / \beta$-catenin pathway in bone remodeling) in cocultured PC 3 cells, redirecting $\beta$-catenin toward the FoxO pathway in osteoblasts and activating the transcription of factors involved in counteracting oxidative stress. In addition, the intrabone inoculation of PCa cells overexpressing HO-1 (PC3HO-1) produced a robust bone remodeling (16). These findings suggested that HO-1 plays a key role in the control of inflammation, oxidative stress, and angiogenesis, which in turn altered the tumor microenvironment impacting on $\mathrm{PCa}$ bone progression.

In this work, we evaluated by histomorphometric analysis of femurs from male BALB/c Hmoxl ${ }^{+/+}$(wild-type [WT]); Hmoxl $^{+/-}$(heterozygous [Het]); Hmoxl ${ }^{-/-}$(knockout [KO]) mice, the involvement of HO-1 on bone remodeling. We also investigated the role of HO-1 deficiency in the communication through released soluble factors between osteoblasts and prostatic cancer cells, using a coculture system of PMOs isolated from the calvaria of the Hmoxl transgenic animals and PC3 cells.

Histomorphometric analysis of femurs of the different groups was carried out to characterize the animal model and evaluate whether the different genetic backgrounds resulted in alterations in the physiology and, therefore, in the morphology of the bone tissue. Our results showed a significant decrease in bone volume, bone density, and trabecular bone density, with an increase in the average distance between trabeculae, in the Hmoxl ${ }^{-/-}$versus Hmoxl ${ }^{+/+}$animals (Figs. 1 and 2A). In agreement with these results, a reduction was also seen in all the static parameters of bone formation, with a total loss of the osteoid surface (OS; used as a bone neoformation parameter), consistent with a reduction in the number of osteoblasts (Figs. 1A and 2B). Accordingly, a decrease in osteoclast number was observed, and the consequent reduction of the static resorption parameters (Figs. 1B and $2 \mathrm{C}$ ).

Considering the differences observed at the morphological level, we next sought to evaluate if these alterations could be explained by changes in the expression of genes related to bone metabolism. For this purpose, PMOs were isolated from the calvaria of the Hmoxl ${ }^{+/+}, H_{m o x l}{ }^{+/-}$, and Hmoxl ${ }^{-/}$animals, and the expression of genes involved in bone physiology was analyzed by real-time quantitative polymerase chain reaction (RT-qPCR). We found a direct correlation between expression levels of Hmoxl and genes such as Run $x$ 2-osteoblast early differentiation associated geneCollal -involved in the deposition of the collagen matrixand $C s f-1, O p g-$ secretion proteins that modulate osteoclast
A
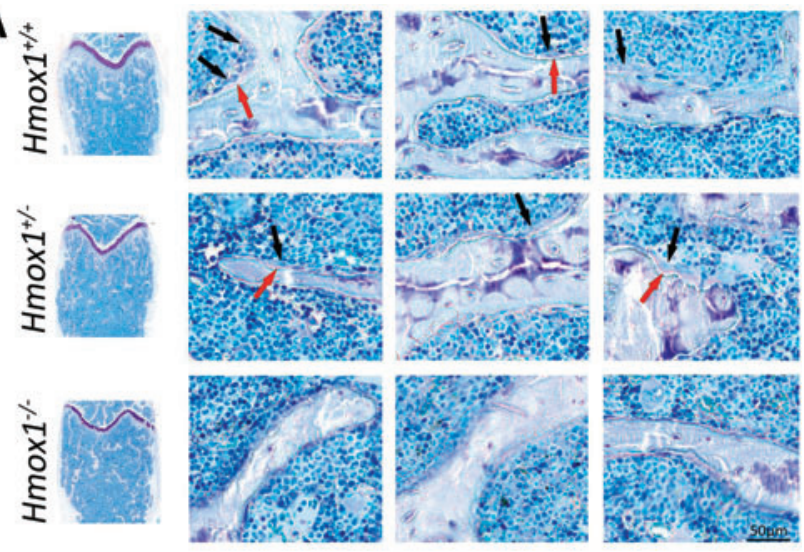

B
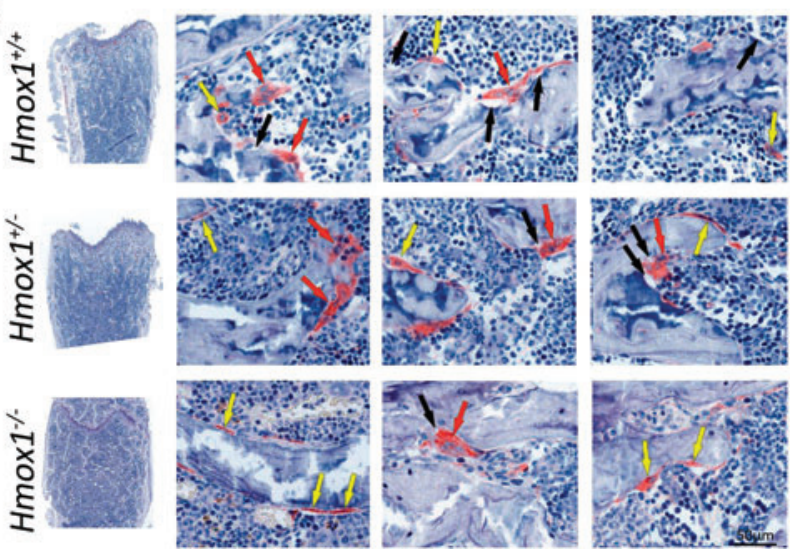

FIG. 1. Histological section of femurs of BALB/c HmoxI$^{+/+}, \boldsymbol{H m o x I}^{+/-}$, and HmoxI $\boldsymbol{I}^{-/-}$mice. (A) Staining with toluidine blue for the analysis of osteoblasts (black arrows) and osteoid (red arrows); or (B) staining for TRAP. Red arrows indicate mature osteoclasts, yellow arrows indicate monocytes, and black arrows show eroded areas. The images at the left column are montages of images taken with $20 \times$ objective. Hmoxl, heme oxygenase-1 gene; TRAP, acid phosphatase tartrate resistant. Color images are available online.

differentiation/activation (Fig. 3A). Other critical molecules involved in the activation and function of osteoclasts, such as $\mathrm{Opn}$-mediates osteoclast adhesion for bone resorption-Il6-osteoclast differentiation/activation modulator-and Rankl—osteoclast differentiation factor, showed a behavioral pattern independent of Hmoxl levels (Fig. 3A).

It was previously reported that HO-1 confers cytoprotection against inflammation and oxidative stress in several animal models (20). Oxidative stress is a natural consequence of the inflammatory process and acts as a modulator of the function of mineralized tissues (63). This impacts bone formation by inhibiting osteoblast differentiation and by promoting apoptosis (2). These effects are mediated, in part, by ROS generated in the context of oxidative stress. Taking this into account, we next evaluated ROS levels in PMOs obtained from Hmoxl ${ }^{+/+}, H_{m o x l} I^{+-}$, and Hmoxl ${ }^{-/-}$mice by flow cytometry (Fig. 3B). A lower percentage of DCF+ cells in the Hmoxl $I^{--}$PMOs were observed when compared with those from the Hmoxl ${ }^{+/+}$or Hmoxl $I^{+-}$animals (Fig. 3B.I). When analyzing the frequency distribution for the DCF 

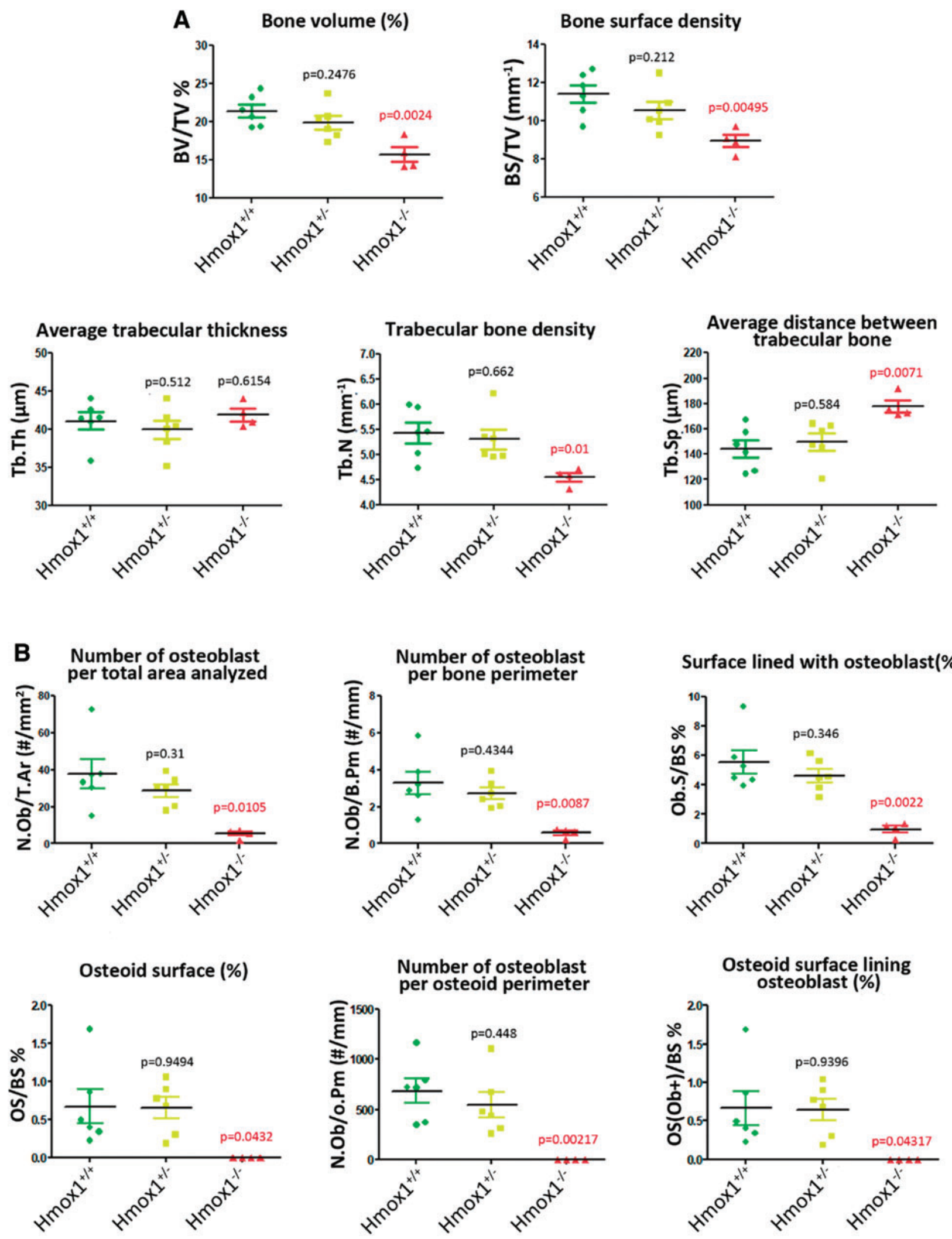

FIG. 2. Histomorphometry analysis of femurs of BALB/c $\mathrm{Hmoxl}^{+/+}(\mathrm{WT}), \mathrm{Hmox}^{+/-}(\mathrm{Het}) ; \mathrm{Hmoxl}^{-/-}$(KO) mice. Dot-plot graphs depicting (A) different bone structural parameters, (B) static formation parameters and (C) static resorption parameters. In each case, the statistical significance ( $p$ value) is expressed with respect to the values obtained for the WT animals. $p$ Value in red indicates significant differences. BS/TV, bone surface/tissue volume; BV/TV, bone volume/tissue volume; ES/BS, eroded surface/bone surface; N.Ob/B.Pm, osteoblasts/bone perimeter; N.Ob/O.Pm, osteoblasts/osteoid perimeter; N.Ob/T.A, osteoblasts/total area; N.Oc/B.Pm, osteoclasts/bone perimeter; N.Oc/B.Pm, osteoclasts/bone perimeter; N.Oc/T.A, osteoclasts/total area; Ob.S/BS, osteoblast surface/bone surface; OS/BS, osteoid surface/bone surface; $\mathrm{Os}(\mathrm{Ob}+) / \mathrm{BS}$, osteoid surface lined with osteoblast/bone surface; Tb.N, trabecular number; Tb.Sp, trabecular separation; $\mathrm{Tb} . \mathrm{Th}$, trabecular thickness; WT, wild type. Color images are available online. 


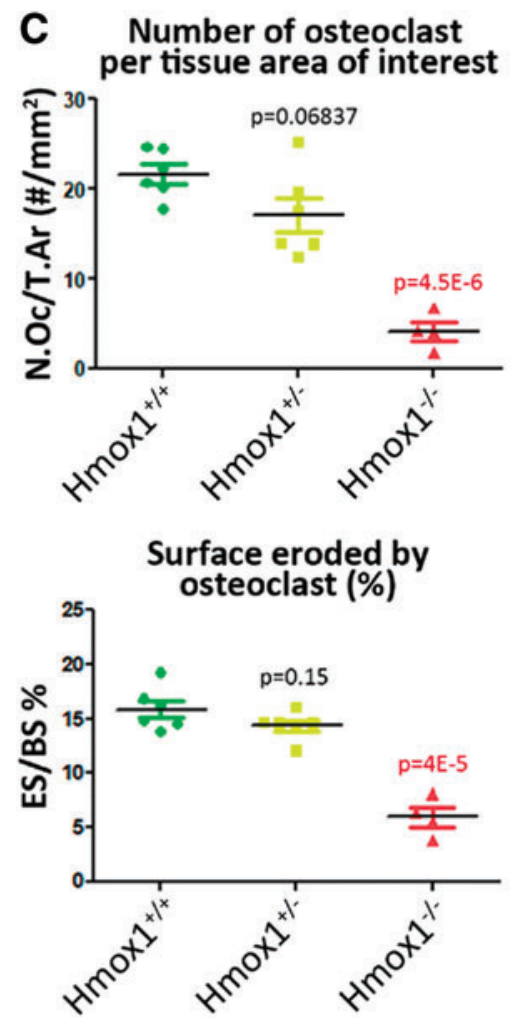

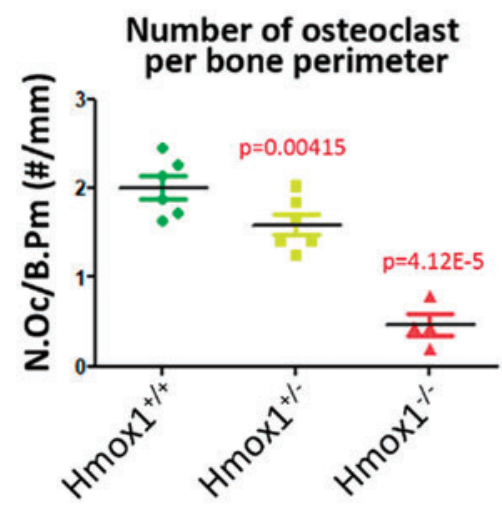

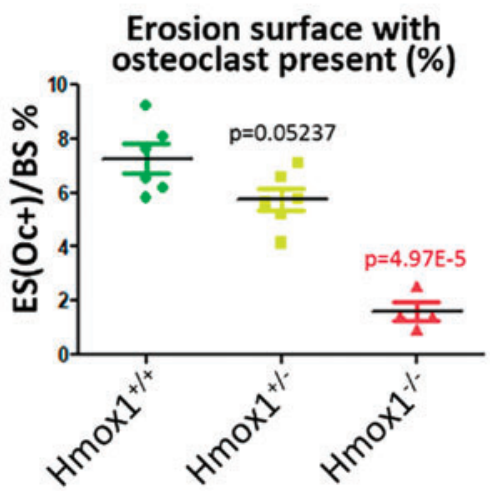

FIG. 2. (continued).
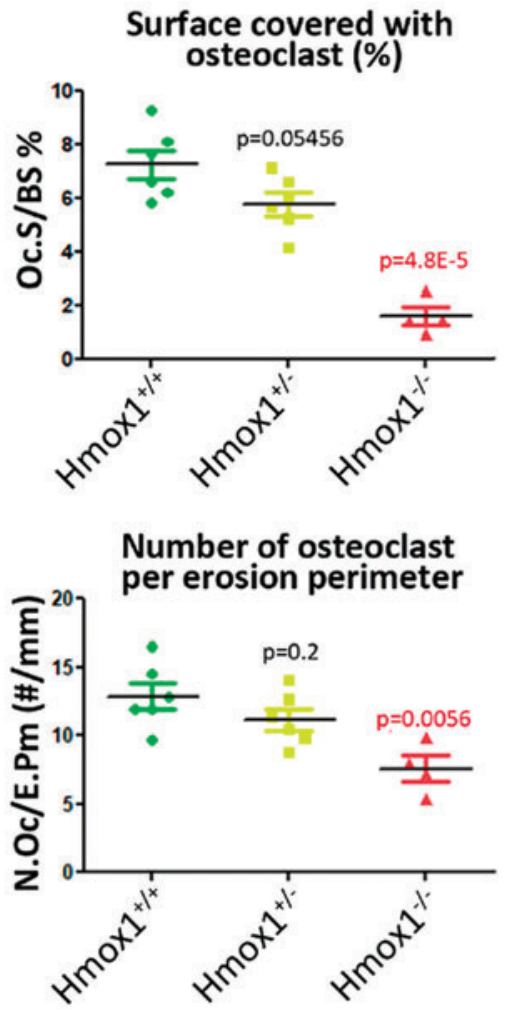

signal intensity (Fig. 3B.II), we identified two cell populations: "High" and "Low." In addition, the "Low" population of $H_{m o x} I^{+/-}$and Hmoxl ${ }^{-/-}$cells had a slightly lower fluorescence intensity compared with Hmoxl ${ }^{+/+}$PMOs. On the contrary, the "High" populations had the same intensity, but the frequency was higher in $H_{m o x} l^{+/}$PMOs when compared with the Hmox $1^{++}$PMOs. The frequency of cells in the "High" population for the Hmox $1^{-/-}$PMOs was barely present (Fig. 3B.III). Overall, these results might suggest that in the PMOs from the Hmoxl heterozygous animals, the increase in the "High" population might be due to the fact that these cells had fewer copies of Hmoxl (compared with WT animals), and therefore, a decreased ability to maintain redox homeostasis. In addition, in the case of Hmox $1^{-1-}$ PMOs, a striking decrease in the "High" population was observed, indicating that HO-1 loss might establish a maximum limit in ROS level tolerance for these cells. However, we cannot discard the possibility that the imbalance in the antioxidant state, produced as a consequence of Hmoxl loss, could trigger the activation of other antioxidant pathways.

Role of Hmox1 expression in osteoblasts upon interaction with PCa cells

Given the morphological, physiological, and genetic differences observed in the bones of animals with the different Hmoxl genetic backgrounds, we next analyzed the effect of the coculture of PC3 cells (pretreated or not with hemin, specific HO-1 chemical inducer) with PMOs isolated from Hmoxl $^{+/+}$, Hmoxl $^{+/-}$, and Hmoxl ${ }^{-/-}$animals to understand the relevance of $\mathrm{HO}-1$ in bone metastases.
First, we compared ROS levels in PMOs from the three groups of animals between the different coculture conditions (Fig. 4A). Only the Hmox $1^{+/-}$PMOs showed an increase in the percentage of $\mathrm{DCF}+$ cells when cocultured with $\mathrm{PCa}$ cells, whether they were pretreated or not with hemin (Fig. 4B). Considering the results from Figures 3B and 4, the stressor effect generated by the presence of PCa cells was evident only in Hmox $1^{+/-}$PMOs due to the diminished regulatory capacity. It is possible given that Hmoxl levels are lower in Hmox $\mathrm{I}^{+/-}$compared with WT animals, this decrease in Hmoxl expression may have more significant consequences, evidenced by increased ROS levels in these cells.

Taking into consideration that a decrease in Hmoxl levels is also seen in WT animals, this reduction in Hmoxl net levels may not be as lower as in Hmox $1^{+/-}$animals, and hence may be sufficient enough to counteract oxidative stress. The next step was to evaluate Hmoxl gene expression in the coculture system. Messenger RNA (mRNA) levels of Hmoxl in both the $H_{m o x} I^{+/+}$and Hmoxl ${ }^{+/-}$PMOs were negatively modulated upon coculture with PC3 cells (pretreated or not with hemin) (Fig. 4C.II, III). Given that Hmoxl expression levels in PMO KO were extremely low (Fig. 4C.I), RT-qPCR quantification for this gene in PMO KO cocultured with PC3 cells was not sensitive enough for an accurate Hmoxl determination.

When analyzing the coculture effect on the expression of bone remodeling genes (Fig. 5A) in the Hmox $1^{+/+}$PMOs, we found that the presence of tumor cells had a negative impact on $O p g$ and $C s f-1$ expression, and this effect was maintained when PCa cells were pretreated with hemin (Fig. 5B-D). Furthermore, Rankl expression was positively regulated by the coculture (Fig. 5). This increase in addition to the 

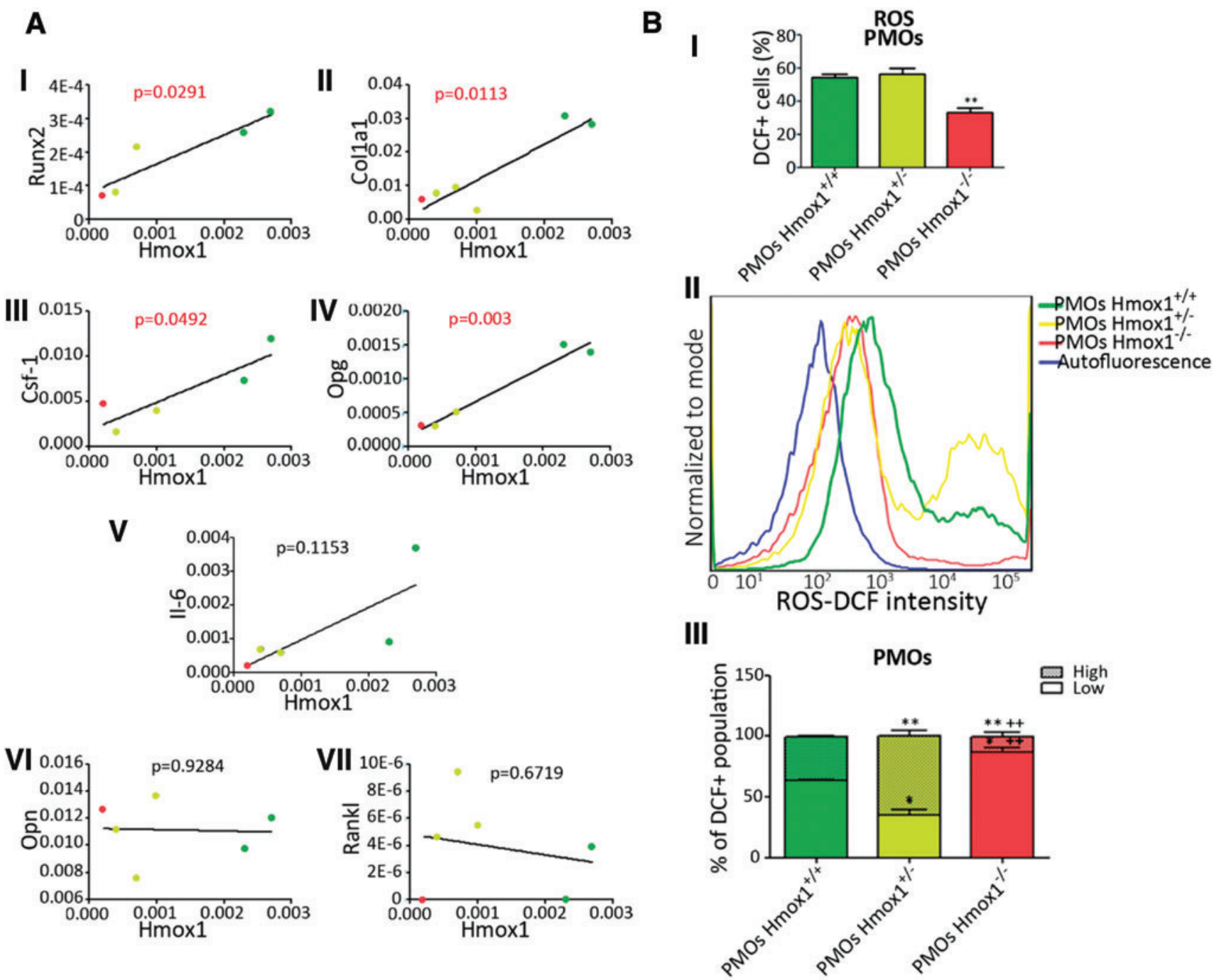

FIG. 3. Expression of bone remodeling genes and oxidative stress levels in primary mouse osteoblasts isolated from $\boldsymbol{H m o x I}^{+/+}, \boldsymbol{H m o x I}^{+/-} ; \boldsymbol{H m o x I}^{-/-}$mice calvariae. (A) Correlation in the expression of genes involved in bone remodeling with respect to Hmox1. Gene expression levels (relative to 36b4) measured by RT-qPCR: (I) Runx2; (II) Colla1; (III) Csf1; (IV) Opg; (V) Il-6; (VI) Opn and (VII) Rankl, expressed as a function of the levels of Hmoxl in PMOs isolated from BALB/c Hmoxl $1^{+/+}, H \operatorname{mox} 1^{+/-}$, and Hmoxl $1^{-/-}$mice. Color of the dots represents the specific genotype of the Hmox $1^{+/+}$ (green dots), Hmoxl ${ }^{+-}$(yellow dots), and Hmoxl $1^{-/}$(red dots). The data were subjected to a linear regression. In each case, the statistical significance ( $p$ value) is expressed for the linear regression obtained. $p$ Value in red indicates significant differences. (B) ROS levels in PMOs measured by flow cytometry in the FITC channel, using DCFDA as a probe. (I) shows the percentage of FITC+ cells for PMOs Hmoxl $1^{+/+}, H_{m o x}{ }^{+/-}, H_{m o x} 1^{-/-}$; (II) shows a representative histogram for FITC intensity for PMOs $H_{m o x} I^{+/+}$(green), Hmoxl ${ }^{+/-}$(yellow), Hmoxl ${ }^{-/-}$(red), and autofluorescence (blue); (III) shows the percentage distribution of FITC + cells in each intensity population (High or Low). Results are expressed as mean \pm SD. Hmox ${ }^{+/+}:{ }^{*} p<0.05 ; * * p<0.01$. Statistical difference with respect to the PMOs $\operatorname{Hmoxl}^{+/-}$; ${ }^{++} p<0.05$. Colla1, collagen type I alpha 1 chain; CSF-1, colony stimulating factor 1; DCFDA, 5-(and-6)-carboxy-2',7'-dichlorofluorescein diacetate; FITC, fluorescein isothiocyanate; PMOs, primary mouse osteoblasts; ROS, reactive oxygen species; RT-qPCR, real-time quantitative polymerase chain reaction; SD, standard deviation. Color images are available online.

decrease in $O p g$ would cause an imbalance in the Rankl/Opg ratio that might favor the osteoclast activation in the bone microenvironment (Fig. 5A). Although hemin pretreatment of tumor cells had no further effect on $O p g$ expression in Hmox $1^{+/+}$PMOs after coculture, it was able to prevent the increase in Rankl expression. In line with this, the coculture with PCa cells pretreated with hemin induced an increase in the expression of Runx2 in Hmox1 $1^{+/+}$PMOs (Fig. 5B), leading toward a less pro-osteoclastic profile. Other genes such as Il-6 suffered a small decrease, which was only significant compared with the coculture with PC3 cells pretreated with hemin (Fig. 5B). Collal and Opn were not affected in any of the assayed conditions (Fig. 5B).

Regarding Opg, Runx2, Csf-1, and Opn expression in Hmox $1^{+/-}$PMOs (Fig. 5C), we observed the same effect described for Hmox $1^{+/+}$PMOs. These results suggest that the response is not affected by Hmoxl basal levels in bone cells. Moreover, even in Hmox $1^{-/-}$PMOs, the coculture effects on 

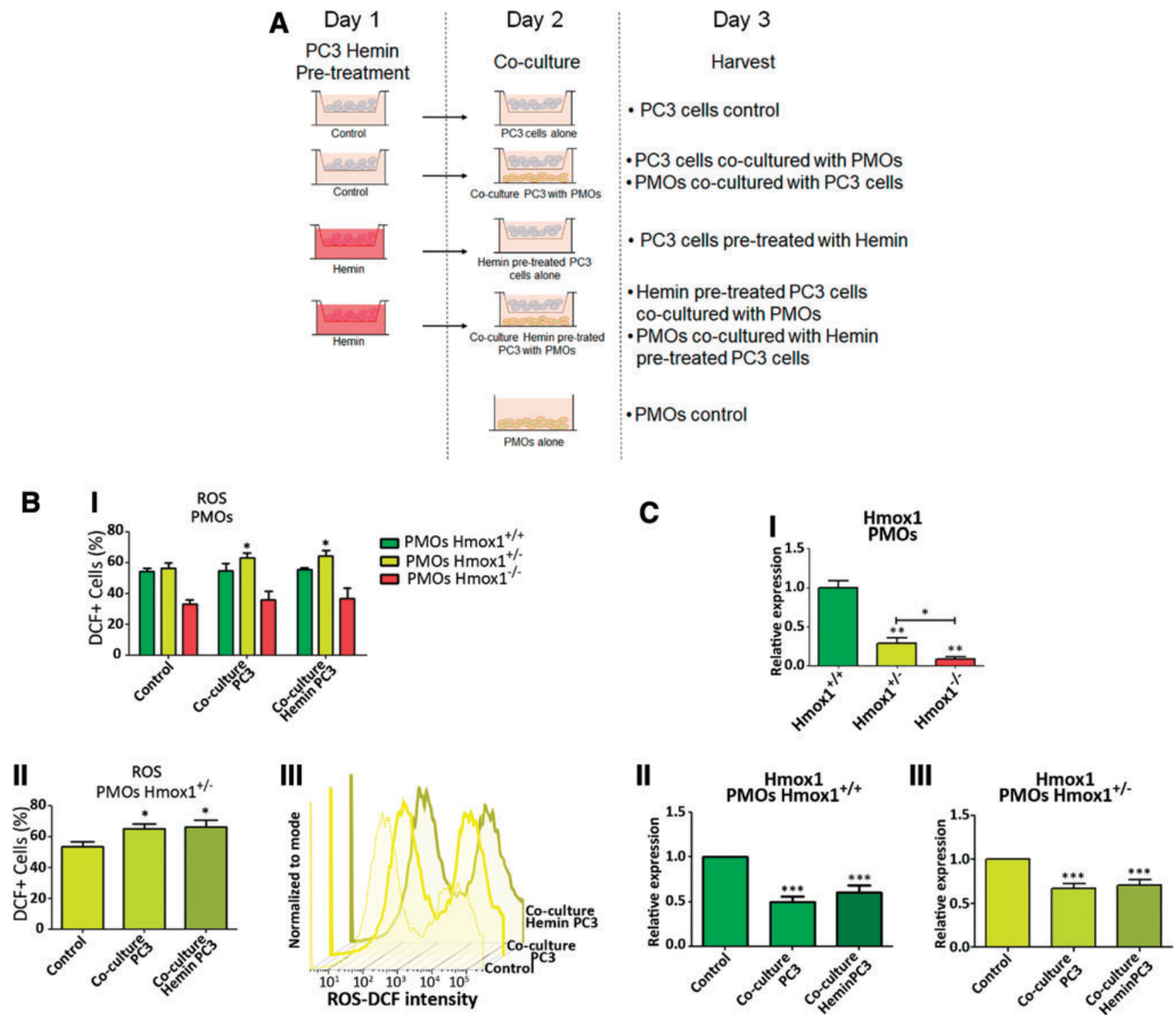

FIG. 4. Co-culture of primary mouse osteoblasts isolated from $\mathrm{HmoxI}^{+/+}, \mathrm{HmoxI}^{+/-}, \mathrm{HmoxI}^{-/-}$mice calvaria and PC3 cells. (A) Coculture system representation. (B) Upper panel (I) depicts levels of ROS measured in PMOs (HmoxI ${ }^{+/+}$, $H_{m o x} I^{+-}$, Hmoxl $^{-/-}$) under the different coculture conditions by flow cytometry, in the FITC channel using a DCFDA probe. Lower left panel (II) shows FITC+ cells in Hmox ${ }^{+/-}$PMOs cultured under the experimental conditions detailed in the figure. Lower right panel (III) shows representative histograms for the intensity of FITC in PMOs $\mathrm{Hmoxl}^{+-}$in the coculture experimental conditions. $* p<0.05$. (C) Upper panel (I) shows the expression levels of Hmoxl assessed by RT-qPCR in PMOs. Lower panels show the coculture effect with PC 3 cells or PC 3 cells pretreated with hemin $(50 \mu M ; 24 \mathrm{~h})$, on the expression of Hmoxl in PMOs (II) Hmoxl ${ }^{+/+}$ or (III) $\mathrm{Hmoxl}^{+/-}$. The values were relativized using $36 \mathrm{~B} 4$ as a reference gene and normalized with respect to the control condition. Results are expressed as mean \pm SD. $* p<0.05 ; * * p<0.01 ; * * *<0.001$. Color images are available online.

Opg, Runx2, and Opn expression are preserved, whereas the expression of $C s f-1$ is only affected by the presence of tumor cells pretreated with hemin (Fig. 5D). The loss of Hmoxl avoided the effect of the coculture on $I l-6$ expression, evidenced by the lack of changes in $\operatorname{HmoxI}^{+/-}$and Hmoxl ${ }^{-/-}$
PMOs, under the tested conditions (Fig. 5C, D). Conversely, an increase in Collal expression was evident in $\mathrm{Hmoxl}^{+/-}$ PMOs when cocultured in the presence of hemin pretreated PC 3 cells (Fig. 5C). This change in Collal expression could be evidenced in $\mathrm{Hmoxl}^{+/-}$PMOs due to the lower basal levels of

FIG. 5. Expression of bone remodeling genes under co-culture of primary mouse osteoblasts isolated from $\mathrm{HmoxI}^{+/+}$, HmoxI $^{+-}$, Hmoxl $^{--}$mice calvaria and PC3 cells. (A) Schematic representation of soluble factors implicated in the communication between PCa and bone cells. Expression levels of (I) Opg, (II) Rankl, (III) Runx2, (IV) Collal, (V) Csf-1, (VI) Il-6, and (VII) Opn assessed by RT-qPCR in (B) Hmoxl $I^{+/}$PMOs, (C) Hmoxl ${ }^{+/-}$PMOs, or (D) Hmoxl $1^{-/-}$PMOs grown alone or in coculture with PC3 cells or PC 3 cells pretreated with hemin $(50 \mu M ; 24 \mathrm{~h})$. The values were relativized using $36 B 4$ as a reference gene and normalized with respect to the control condition. Results are expressed as mean \pm SD. ${ }^{*} p<0.05$; ${ }^{* *} p<0.01$; $* * * p<0.001$. PCa, prostate cancer. Color images are available online. 


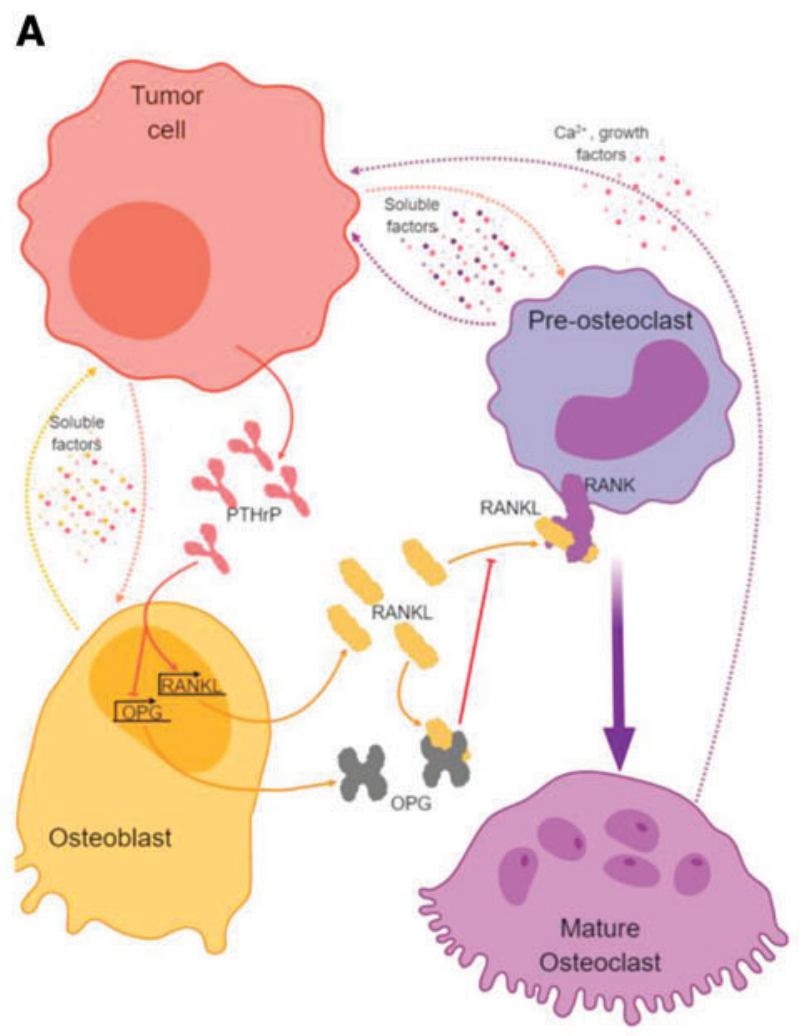

B I

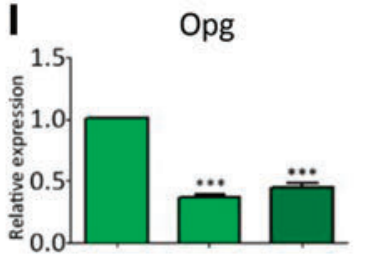

III

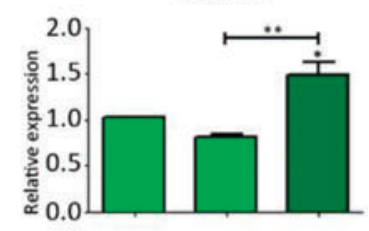

V

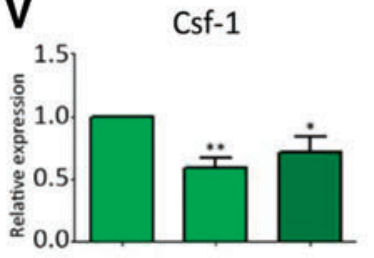

VII

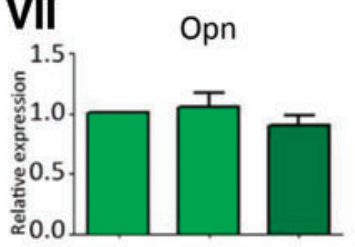

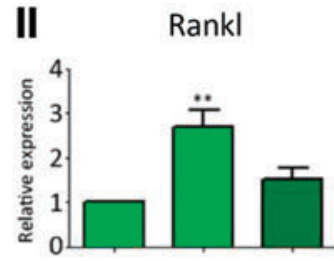

IV Col1a1

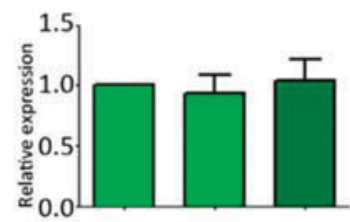

VI $\quad$ II-6

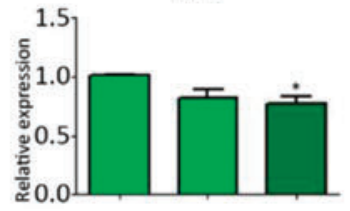

PMOs Hmox-1*/*

$\square$ Control

$\square$ Co-culture PC3

$\square$ Co-culture Hemin PC3
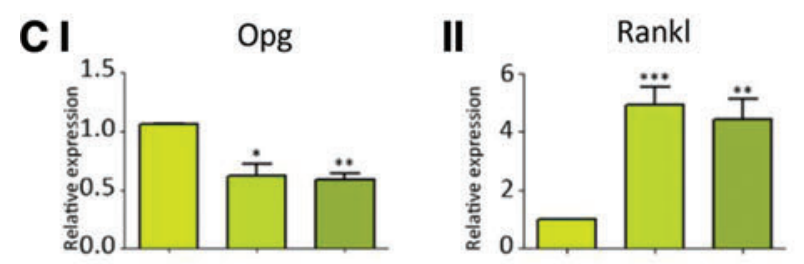

D
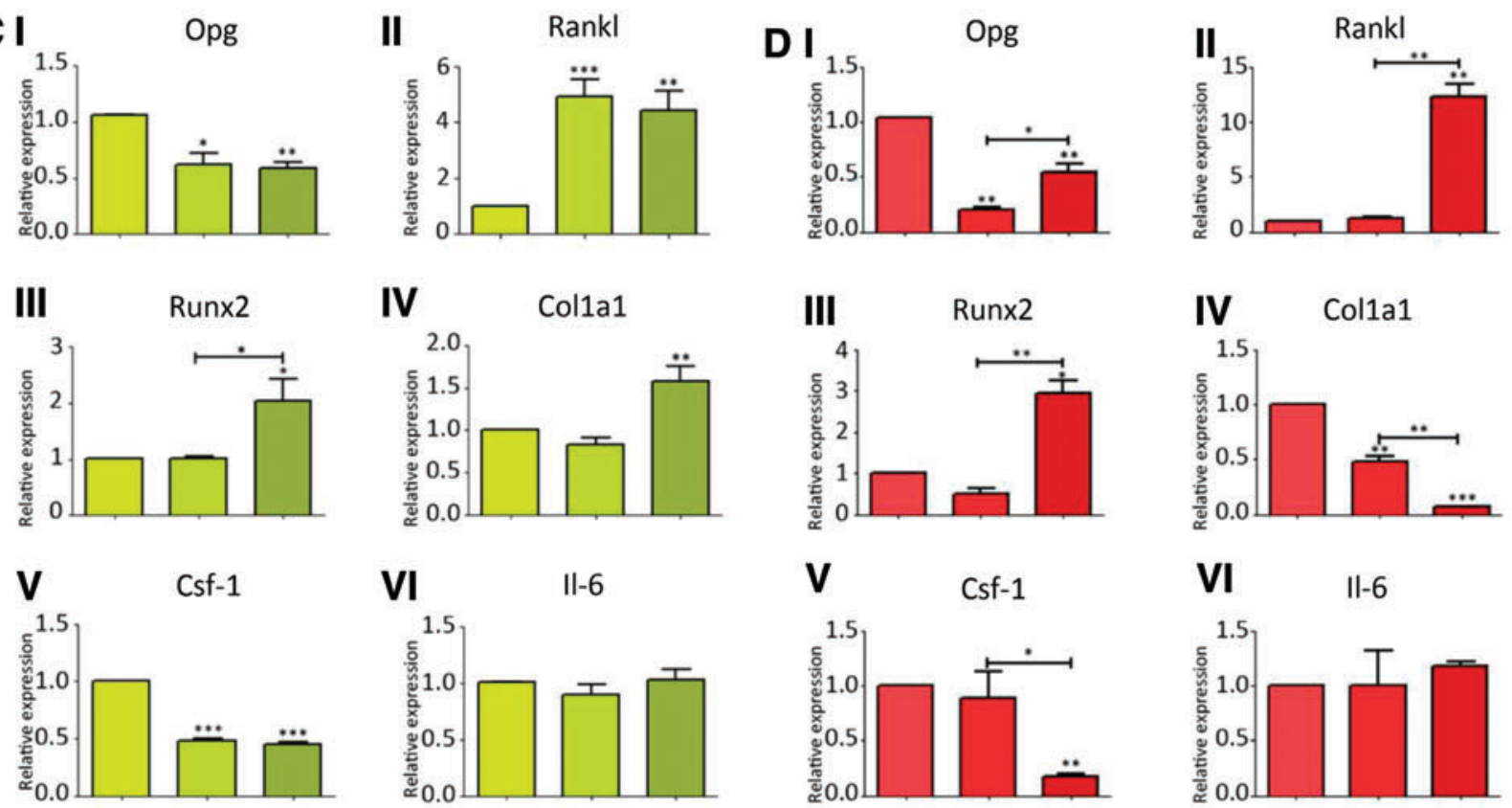

V

Csf-1
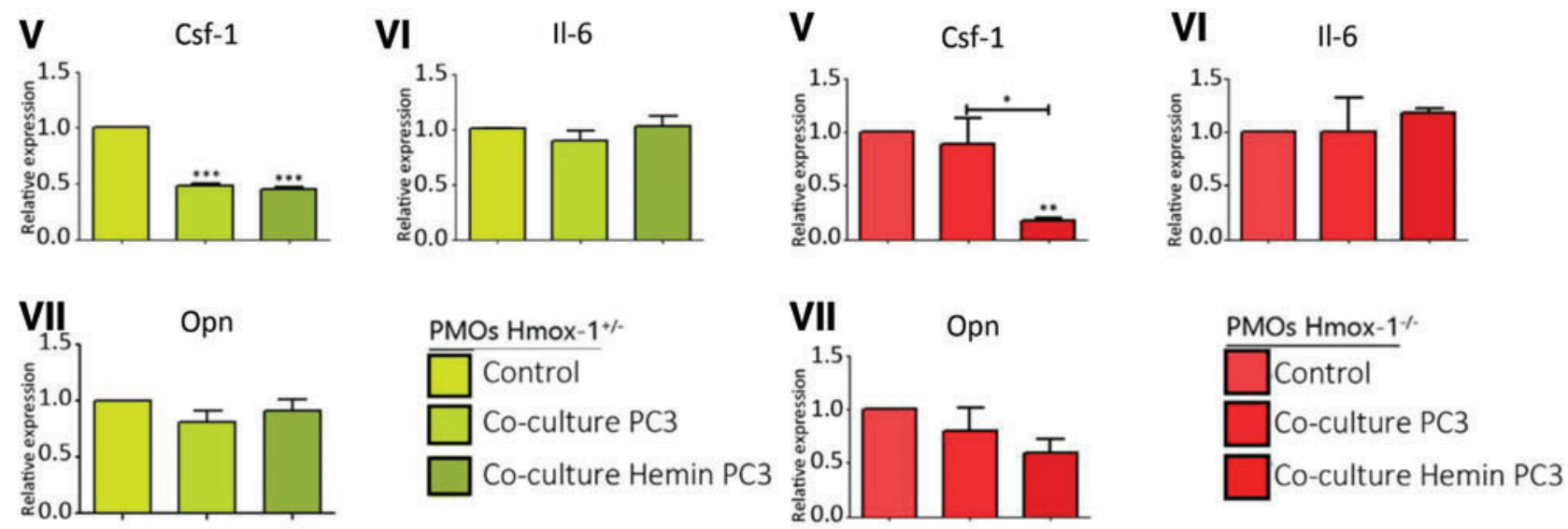
this gene with respect to Hmoxl ${ }^{+/+}$PMOs. In the case of Hmox $I^{-/-}$PMOs, both experimental conditions led to a decrease in the expression of Collal (Fig. 5D), showing a change in the coculture effect due to the lack of HO-1 in PMOs.

Although the increase in Rankl expression due to the coculture effect with PCa cells is still observed in Hmoxl ${ }^{+-}$ PMOs (Fig. 5C), the coculture with hemin pretreated tumor cells was not able to prevent Rankl induction, as observed in Hmox $I^{+/+}$PMOs. On the contrary, the coculture with PCa cells was not able to induce the expression of Rankl in osteoblasts lacking Hmoxl, while the presence of hemin pretreated tumor cells caused a significant overexpression of Rankl in Hmoxl ${ }^{-1-}$ PMOs (Fig. 5D). These results imply that the coculture effect on Rankl expression is modulated by HO-1 not only in the tumor cell but also in the osteoblast.

In the same way, the effect of the coculture was assessed in PCa cells. First, HMOX1 levels were measured, resulting in no significant alteration when the tumor cells were cocultured with the PMOs (Fig. 6A). When tumor cells were pretreated with hemin, the induction of $H M O X 1$ was maintained in

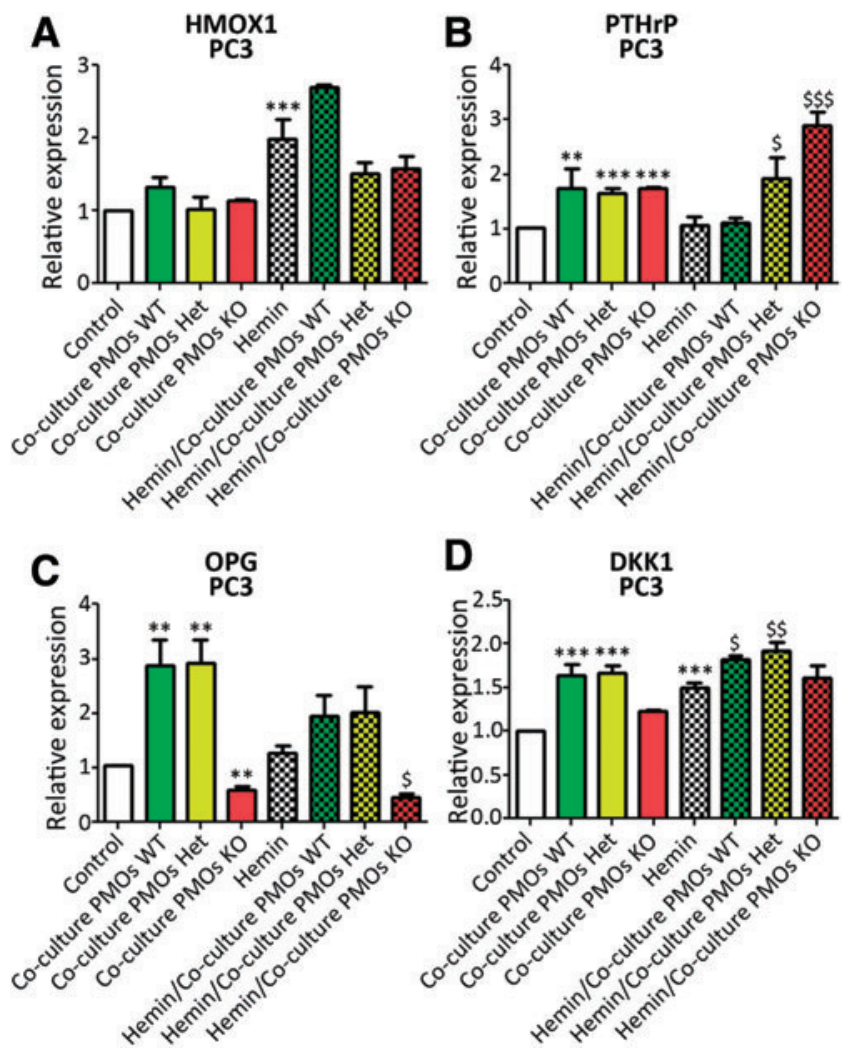

FIG. 6. Gene expression analyses in PC3 cells growing in co-cutlure with primary mouse osteoblasts isolated from $\mathrm{HmoxI}^{+/+}, \mathrm{HmoxI}^{+/-}, \mathrm{HmoxI}^{-1-}$ mice calvaria. EXpression levels of (A) HMOX1, (B) PTHrP, (C) OPG, and (D) $D K K 1$, assessed by RT-qPCR in PC3 cells pretreated or not with hemin $(50 \mu M ; 24 \mathrm{~h})$, grown alone or in coculture $(24 \mathrm{~h})$ with PMOs HmoxI $I^{+++} ; H_{m o x I}{ }^{+-}$; and Hmoxl ${ }^{-/}$. The values were relativized using PPIA as a reference gene and normalized with respect to the control condition. Results are expressed as mean \pm SD. Statistical significance with respect to control: ${ }^{* *} p<0.01 ; \quad * * * p<0.001$; or hemin: ${ }^{\$} p<0.05 ; \quad{ }^{\$} p<0.01$; ${ }^{\$} \$ p<0.001$. DKK1, inhibitor of $\mathrm{Wnt} / \beta$-catenin pathway in bone remodeling. Color images are available online. comparison with the coculture with $H \operatorname{mox} I^{+/+}$PMOs, while the coculture with both Hmoxl $I^{+/-}$and Hmoxl ${ }^{-/-}$PMOs partially reversed the effect of the hemin pretreatment on HMOX1 levels in the PCa cells (Fig. 6A).

As previously mentioned, $\mathrm{PTHrP}$ can be produced by tumor cells with implications not only for the tumor cell but for bone physiology as well (44). Under our experimental conditions, PTHrP expression was increased in PC3 cells cocultured with PMOs, independent of the genotype (Fig. 6B). Hemin pretreatment was able to prevent the induction of PTHrP in the coculture with Hmox ${ }^{+/+}$PMOs. This preventive capacity of hemin pretreatment was not only lost when tumor cells were cocultured with $\mathrm{HmoxI}^{+/-}$PMOs but also enhanced the coculture effect when tumor cells were grown in the presence of Hmoxl ${ }^{-1-}$ PMOs (Fig. 6B).

The PC3 cells express $O P G$ (27). As observed for $P T H r P$, $O P G$ expression increased in tumor cells that had been cocultured with $\mathrm{Hmoxl}^{+/+}$or Hmoxl $\mathrm{I}^{+-}$PMOs, and this effect was prevented by hemin pretreatment (Fig. 6C). Besides, the coculture with $\mathrm{Hmoxl}^{-/-}$PMOs negatively affected the expression of $O P G$ in the tumor cells, independently of whether they had been pretreated with hemin (Fig. 6C).

In the case of DKK1, a critical factor in bone remodeling, acting as an inhibitor of the $\mathrm{Wnt} / \beta$-catenin pathway (45), its expression was upregulated in tumor cells cocultured with Hmoxl $I^{+/+}$or Hmoxl $1^{+/-}$PMOs, but not when cocultured with Hmoxl $^{-1-}$ PMOs (Fig. 6D).

In summary, hemin pretreatment modulated the response of tumor cells to the coculture with the PMOs, and this modulation was different depending on the PMO Hmoxl genetic background. This clearly suggests that the HO-1 level in the PMOs is not only important for their physiology but is also relevant for their interaction with the tumor cells.

\section{Discussion}

Bone is a dynamic tissue that undergoes homeostatic remodeling mediated by the balanced activities of osteoblasts and osteoclasts (34). HO-1 plays a critical role in the physiology of this process $(34,55,61)$. HO-1 was shown to maintain bone mass during physiological bone remodeling (34).

The histomorphometric analysis of mice femurs for the different genetic backgrounds $\left(\right.$ Hmoxl $^{+/+}$, Hmoxl $^{+/-}$, and $H_{m o x} I^{-l}$ ) presented in this work showed a decrease in bone volume concomitant with the loss of Hmoxl. In line, a lower number of osteoblasts were observed, with the consequent reduction of osteogenic parameters. These results are consistent with the functions previously described for HO-1 (4, $60,61)$. It was reported that HO-1 expression and activity are essential for the differentiation of MSCs toward an osteoblastic lineage, as well as vital for their growth (61). In addition, the inhibition of HO- 1 favors the differentiation of MSCs toward the formation of adipocytes, with a decrease in osteoblast formation $(4,60,61)$.

Although HO-1 induction was demonstrated to impair osteoclast differentiation $(17,34,71)$ in transgenic mice, we showed that Hmoxl deficiency downregulated osteoclast number and activity. These results may appear contradictory at first. However, and taking into account the physiological context, the osteoblastic lineage is the main modulator of osteoclast differentiation and activation, so that the observed 
decrease in osteoblast number and activity in Hmoxl-deficient mice may explain the decrease observed in both bone metabolism and osteoclast differentiation and activation. These results are further supported by the altered expression found in genes involved in osteoblast differentiation and/or regulation of bone physiology, concurrent with the general decrease in bone metabolism.

It was reported that the reduction in ROS levels mediated by HO-1 canonical activity, allowed the restoration of osteoblastic markers $(4,61)$. The PMOs isolated from the calvaria of mice used in this study showed heterogeneous levels of ROS within each genotype, identifying two populations with Low- and High-ROS levels. In the case of Hmox $1^{-/-}$PMOs, a striking decrease in the "High" population was observed, indicating that HO-1 loss might establish a maximum limit in ROS level tolerance for these cells, acting as a positive selection factor on cells with low levels of ROS and therefore with a decreased oxidative metabolism.

Of note, when working with PMOs, it is worth mentioning that the isolation of this particular cell linage requires HO-1 for differentiation $(4,60,61)$; hence, Hmox 1 deficiency might also severely impact on the number of PMOs. This evidence is in line with the histomorphometry analysis performed in this work, depicting a decrease in bone metabolism when analyzing the osteoblasts from femurs of KO Hmox 1 transgenic mice compared with WT and/or heterozygous femurs. Whether the High-ROS level cell population, during the animal development, did initially exist in abundance and was then lost - unable to survive in a high ROS condition - is still to be elucidated.

Regarding the metastatic process, resorption may be a necessary step for tumor cell homing to bone (69). The consequent bone destruction releases growth factors such as transforming growth factors $\beta$ (TGF- $\beta$ s) and BMPs from the mineralized bone matrix, further enhancing tumor growth and survival in a vicious cycle (22). Tumor cells can stimulate osteoclast activity by directly altering the RANKL/OPG ratio, or secreting signaling molecules such as PTHrP to stimulate RANKL production by osteoblast $(35,66)$.

Considering the involvement of HO-1 in osteoblast differentiation (60), we next studied the effect of cocultures of human PCa cells (pretreated or not with hemin) and the WT or Hmoxl-deficient PMOs. PCa cell coculture altered PMO gene expression, leading toward a pro-osteoclastogenic profile over an osteoblastic function. Hemin pretreated tumor cells could be modulating the interaction by soluble factors of cancer cells with PMOs, leading toward a more proosteoblastic profile. The observed changes on PMOs may be partly explained by the expression changes in $\mathrm{PTHrP}$ in the tumor cells. PTHrP was first isolated from human carcinomas $(26,29)$ and it is one of the main agents for the humoral hypercalcemia associated with various malignancies (19).

PTHrP is structurally associated with PTH, a hormone of vital importance in calcium metabolism (53). PTHrP is a key factor in osteolytic bone metastasis, it increases the production of RANKL and decreases the secretion of OPG from the osteoblasts and stromal cells (30), favoring osteoclastogenesis; however, its direct effects on osteoclasts remain elusive. In addition, breast and $\mathrm{PCa}$ cells that produce osteolytic metastases (i.e., MDA-MB-231, MDA-MB-435s, PC3) secreted PTHrP $(23,68)$. These results suggest that PTHrP could play a pivotal role in bone metastases formation and/or development. Conversely, engineered overexpression of PTHrP in breast or PCa cells increased metastases to the bone compartments and osteoclast-mediated bone destruction at the tumor/bone interface $(24,65)$.

Of note, PTHrP overexpression did not affect the formation of metastases to nonbone sites (24), and a PTHrP neutralizing antibody had no effect on visceral metastases caused by SBC-5 cells (43), suggesting an exclusive role of PTHrP on bone metastases (19). These results highlight the involvement of HO-1 in bone and tumor cell communication mediated by soluble factors. It is well known that PTHrP negatively regulates OPG (32). However, our results showcased that when PMOs, WT, were cocultured with PC3 cells pretreated with hemin, no changes were observed in $\mathrm{PTHrP}$ in PC3 cells, but Opg was downregulated in the PMOs. Thus, Opg modulation is clearly affected by other factors. In this regard, DKK1 might be involved in Opg downregulation in PMOs. DKK1 stimulates growth and osteolytic bone metastasis in PCa $(50,57)$.

Patients with multiple myeloma have DKK1 increased levels in the bone compartment, and thus, it has been proposed as an osteoblast suppression mechanism $(19,58)$. Furthermore, PC3 cells express and release DKK1 and silencing of this molecule resulted in an osteolytic to osteoblastic phenotypic shift $(10,50)$. DKK1 inhibits OPG release from osteoblasts (50). Thus, the decrease in Opg in WT and Het PMOs could be partly explained by the increase in $D K K 1$ expression in PC3 cells when cocultured with PMOs. On the contrary, a drop in Opg expression is also seen in KO PMOs, but in this case, it appears not related to the DKK1 produced by the tumor cell, since no changes are seen in $D K K 1$ expression in PC3 cells when cocultured with KO PMOs. In line with these results, OPG increases in human bone metastases compared with both primary tumor and nodule metastasis (8). PC3 cells express OPG (28), however, they do so at significantly lower levels compared with bone marrow stromal cells (47). This might suggest that beyond OPG bone function, the observed changes in OPG levels in malignant cells could have direct implications on the tumor since OPG can act as a decoy TRAIL receptor decreasing apoptosis mediated by this factor (27).

Figure 7 summarizes our proposed model on the crosstalk between tumor cells and PMOs, where the increase in PTHrP levels in tumor cells by the coculture stimulates Rankl expression in the PMOs $\left(H_{m o x} I^{+/+}\right.$and $\left.H m o x I^{+/-}\right)$. This mechanism would favor the osteoclast differentiation and activation in the bone microenvironment. Hemin pretreatment of PCa cells interferes in the interaction with bone cells, preventing the stimulation of PTHrP in the tumor cell and the consequent change in Rankl levels in Hmox $1^{+/+}$ PMOs, favoring a pro-osteoblastic profile. This modulatory effect is lost when compared with the Hmox $1^{+/-}$PMO coculture, where despite hemin pretreatment, the induction of PTHrP in the tumor cell is maintained and therefore Rankl increases in the Hmoxl ${ }^{+/}$PMOs. Finally, this mechanism results less sensitive in Hmox $1^{-1-}$ PMOs, since a greater increase in PTHrP levels in the tumor cell is required for an increase in Rankl levels in the Hmox $1^{-/-}$PMOs to be evident (Fig. 7).

The molecular mechanisms that govern the distortion of the bone remodeling process occurring in metastatic cancer invading the bone are still poorly understood. The present 


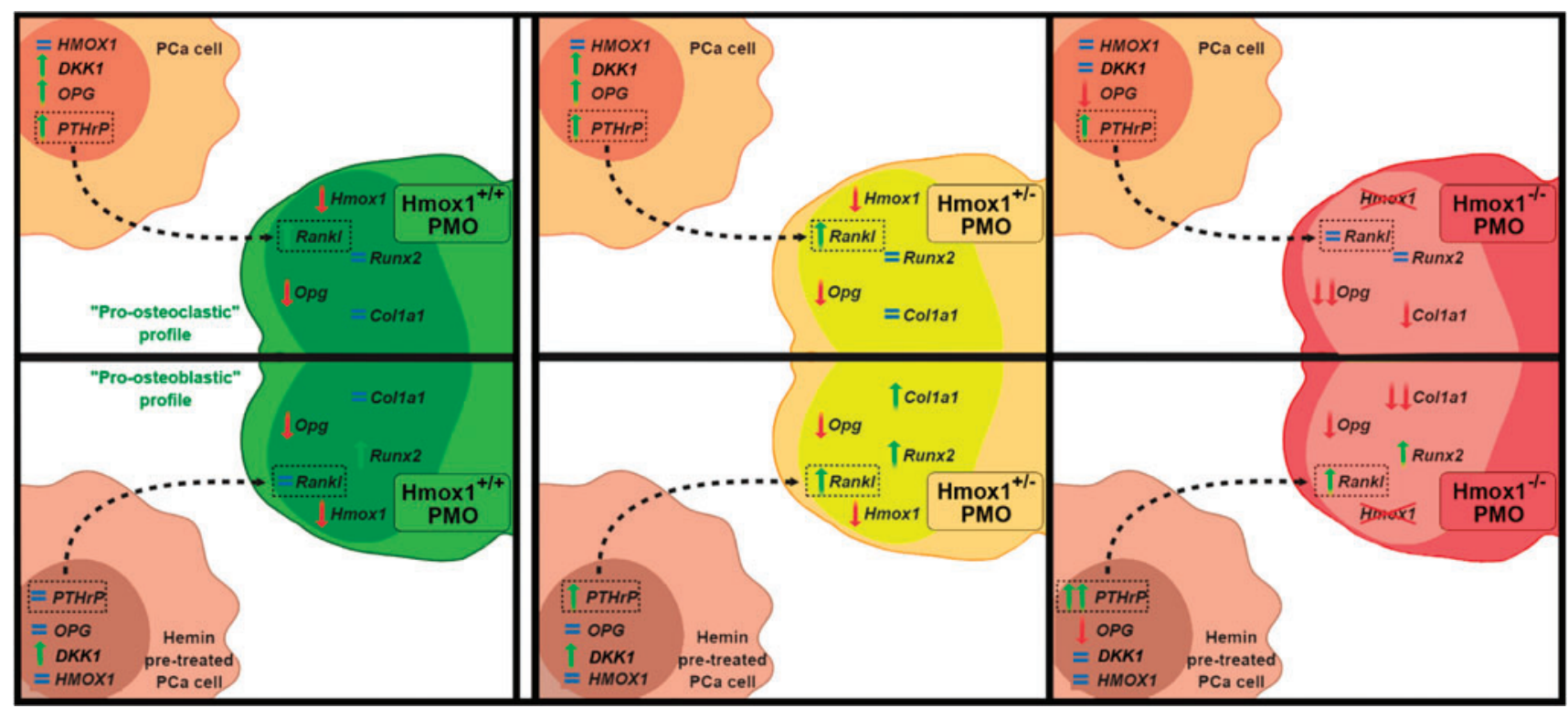

FIG. 7. Schematic representation of the proposed model for the bone-associated genes affected by the crosstalk between tumor cells and PMOs, where the increase in the PTHrP levels in tumor cells due to the coculture could be acting on the PMOs $\left(H_{m o x} I^{+/+}\right.$and $\left.{ }^{+/}\right)$, stimulating Rankl expression. This mechanism would favor the osteoclast differentiation and activation in the bone microenvironment. Hemin pretreatment of PCa cells interferes with the interaction with bone cells, preventing the stimulation of PTHrP in the tumor cell and the change in Rankl levels in $H m o x 1^{+/+}$PMOs, leading toward a higher pro-osteoblastic profile. This modulatory effect is lost when compared with the coculture with the Hmox ${ }^{+/-}$PMOs, where despite hemin pretreatment, the induction of PTHrP in the tumor cell is maintained, and therefore, Rankl increases in the Hmox $1^{+-}$PMOs. This mechanism appears as less sensitive in $H m o x 1^{-/}$PMOs, since a greater increase in PTHrP levels in the tumor cell is needed for an increase in Rankl levels in the Hmox ${ }^{-/-}$PMOs. PTHrP, parathyroid hormone-related protein. Color images are available online.

results reveal the importance of $\mathrm{HO}-1$ expression in bone, not only for the physiology of bone cells but also in the modulation of the communication between PMOs and PCa cells by soluble factors, where PTHrP/RANKL appear as a critical axis.

\section{Materials and Methods}

\section{Animals}

All animal experiments were conducted in accordance with the Animal Research: Reporting of In Vivo Experiments guidelines. Eight-week-old male BALBc/Hmox $1^{+/+}$, Hmox $1^{+/}$, or Hmox $1^{-/-}$mice, initially provided by Dr. Saw Feng-Yet, were housed in the animal facility of the Experimental Obstetrics and Gynecology of the Medical Faculty, Otto-von-Guericke University, Magdeburg.

\section{PMO isolation}

PMOs were isolated from the calvaria of mice (three per group per experiment) following the procedure described by Bakker and Klein-Nulend (3), with slight modifications. In brief, after dissection, calvarias were cut into small pieces and digested for $30 \mathrm{~min}$ in a shaking incubator at $37^{\circ} \mathrm{C}$ in $4 \mathrm{~mL}$ of $\alpha$-MEM containing $2 \mathrm{mg} / \mathrm{mL}$ collagenase $\mathrm{P}$ (Roche Diagnostic GmbH, Mannheim, Germany). After this time, the last step was repeated by renewing the collagenase solution $\mathrm{P}$. Then, the bone pieces were incubated $(30 \mathrm{~min}$ in a shaking incubator at $37^{\circ} \mathrm{C}$ ) in a solution of $2.5 \%$ trypsin plus $0.1 \%$ EDTA (Life Technologies, Inc.) in phosphate-buffered saline (PBS). A final incubation with collagenase $\mathrm{P}$ solution was performed $\left(30 \mathrm{~min}\right.$ in a shaking incubator at $\left.37^{\circ} \mathrm{C}\right)$. The bone fragments were rinsed with $\alpha$-MEM plus penicillin, streptomycin, and $10 \%$ fetal bovine serum (FBS). This last procedure was repeated three times, each time. Finally, the bone pieces were plated in three $25 \mathrm{~cm}^{2}$ flasks containing $\alpha$-MEM plus penicillin, streptomycin, and $10 \%$ FBS. Once the cells migrated from the bone fragments to the plate and reached the desired confluence, they were trypsinized and replated in culture dishes to perform experiments.

\section{Histomorphometric analysis}

Mice were euthanized and the dissected bones fixed in buffered $4 \%$ formalin ( $\mathrm{pH}: 7.4$ ) for $24 \mathrm{~h}$, rinsed with PBS, and stored in $70 \%$ ethanol until processing. Then were embedded in methyl methacrylate plastic resin and cut into consecutive longitudinal sections at 5 micron thickness for histomorphometric analysis. Osteoblast and osteoclast measurements were performed on toluidine blue and acid phosphatase tartrate-resistant (TRAP)/hematoxylin-stained sections, respectively. Measurements were performed on two sections separated by a distance of $40 \mu \mathrm{m}$, and then, data were pooled. The region of interest was located at the distal metaphysis of the femur starting $150 \mu \mathrm{m}$ proximally from the growth plate and extending $1.3 \mathrm{~mm}$ toward the diaphysis. The measurement area excluded the $150 \mu \mathrm{m}$ area adjacent to the cortical bone. On the toluidine blue-stained slides, all cancellous bone endosteal surface lengths were measured and categorized as OS, or osteoblast surface (Ob.S), in the presence or 
absence of osteoid. For surfaces identified as osteoblast surface, individual osteoblasts were counted and the data pooled. All other surfaces were considered quiescent. For the TRAP-stained slides, osteoclast surface (Oc.S) and/or erosion surface (ES) were identified, surface lengths measured, and the data pooled. For surface identified as Oc.S., the individual TRAP-positive, multinucleated osteoclasts were counted and the data pooled. Surface that was rough and scalloped in appearance, either with or without the presence of osteoclasts, was categorized as ES. The samples were analyzed using a microscope Leica DM 1000 with a $20 \times$ objective, coupled to a Qimaging Bioquant ${ }^{\circledR}$ PV1 Camera for the acquisition of the images (at room temperature; medium: air). The software Bioquant Osteo 2017 was used for imaging and analysis. Images were first captured in Bioquant Image Format (.bif) and then converted to .tif format.

\section{Cell lines}

Human PC3 cells (ATCC ${ }^{\circledR}$ CRL-1435) were obtained from the American Type Culture Collection (Manassas, VA) and routinely cultured in RPMI 1640 (Invitrogen, Carlsbad, CA) supplemented with $10 \%$ FBS.

\section{Hemin pretreatment of PCa cells and coculture system}

An in vitro biocompartment culture system was used to study the interaction between PCa cells and bone as previously described and slightly modified (67). Briefly, on day 0 , PC3 cells were seeded $(100,000$ cell/insert) in sixwell plate cell culture inserts $(0.4-\mathrm{mm}$ pore; Falcon/Becton Dickinson Labware, Franklin Lakes, NJ), and on day 1, they were treated with hemin $(50 \mu M$; Sigma-Aldrich, St Louis, MO), a potent specific inducer of HO-1 (Hemin PC3). Controls received fresh medium. The PMOs were also seeded on day 1 in six-well tissue culture plates (200,000 cells/well). On day 2 , the inserts containing the PC3 cells (pretreated or not with hemin) were extensively washed with PBS. Then, the inserts were placed into tissue culture plates containing the PMOs so that the two different cell types shared the culture medium but were not in physical contact. Coculturing of PC3 cells with PMOs was performed with $\alpha$-MEM plus $2 \%$ FBS for $24 \mathrm{~h}$. On day 3 , the cells were collected and different parameters were analyzed. As control, each cell type (PC3 cells pretreated or not with hemin and PMOs) was grown alone. Cultures were done in triplicate and each experiment was assayed three times.

\section{RNA isolation, complementary DNA synthesis, and quantitative real-time polymerase chain reaction}

Total RNA was extracted from cells using the TRIzol ${ }^{\circledR}$ (Life Technologies, Inc.) reagent followed by RNA extraction with chloroform, precipitation with isopropanol, and washing with ethanol. RNA was then diluted in RNA-free water, quantification was performed by ultraviolet absorbance at $260 \mathrm{~nm}$, and quality checked by measuring absorbance at 260/280 nm (Synergy HT; BioTek Instruments). RNA was storaged at $-80^{\circ} \mathrm{C}$ until use. The RNA was reversed transcribed as follows: $2 \mu \mathrm{g}$ of total RNA was incubated with oligo dTs and RNA-free water $10 \mathrm{~min}$ at $75^{\circ} \mathrm{C}$ and rested $2 \mathrm{~min}$ on ice. Incubation for $30 \mathrm{~min}$ at $37^{\circ} \mathrm{C}$ with dNTPs $(2.5 \mathrm{~m} M)$, DNase I $(2 \mathrm{U} / \mu \mathrm{L})$, and Rnase inhibitor $(40 \mathrm{U} / \mu \mathrm{L})$ in a reaction buffer followed. Afterward, DNAse inactivation for $5 \mathrm{~min}$ at $75^{\circ} \mathrm{C}$ took place. After resting on ice for $2 \mathrm{~min}$, reverse transcriptase $(200 \mathrm{U} / \mu \mathrm{L})$ was added together with Rnase inhibitor $(40 \mathrm{U} / \mu \mathrm{L})$ and complementary DNA (cDNA)-synthesis occurred at $42^{\circ} \mathrm{C}$ for $60 \mathrm{~min}$. Samples were stored at $-20^{\circ} \mathrm{C}$ subsequent to inactivation of reverse transcriptase for $5 \mathrm{~min}$ at $94^{\circ} \mathrm{C}$. Real-time polymerase chain reaction (PCR) amplifications were performed with SYBR Green (Applied Biosystems) and an iQ5 Multicolor RealTime PCR Detection System (BioRad). Each amplification reaction consisted of $1 \mu \mathrm{L} \mathrm{cDNA}, 6.5 \mu \mathrm{L} \mathrm{SYBR}$ Green PCR mastermix, $2 \mu \mathrm{L}$ RNAse free water, $3 \mu \mathrm{L}$ primer mix, and $0.5 \mu \mathrm{L}$ fluorescein $(50 \mathrm{n} M)$. Primers used are listed in Table 1. PPIA and 36b4 were used as internal reference genes. Data obtained were analyzed using the method of $2^{-\Delta \Delta \mathrm{CT}}$ (38).

\section{Assessment of ROS by flow cytometry}

After the coculture, the PMOs were washed twice with PBS and incubated with $6 \mu M$ 5,6-clorometil-2' $7^{\prime}$-dichloro

Table 1. Table of Used Primers Containing the Gene Name, Species, Sequences, and Annealing Temperature

\begin{tabular}{|c|c|c|c|c|}
\hline Gene & Species & Primer $F w\left(5^{\prime}>3^{\prime}\right)$ & Primer $\operatorname{Rv}\left(5^{\prime}>3^{\prime}\right)$ & $\begin{array}{c}\text { Annealing } \\
\text { temperature }\left({ }^{\circ} \mathrm{C}\right)\end{array}$ \\
\hline $36 b 4$ & Mouse & AAGCGCGTCCTGGCATTGTCT & CCGCAGGGGCAGCAGTGGT & 60 \\
\hline Hmoxl & Mouse & AAGAGGCTAAGACCGCCTTC & GCATAAATTCCCACTGCCAC & 60 \\
\hline Runx2 & Mouse & CCGCACGACAACCGCACCAT & AGGCATTTCGGAGCTCGGCG & 60 \\
\hline Rankl & Mouse & ATGGAAGGCTCATGGTTGGATG & AAGAGGACAGAGTGACTTTATGGG & 60 \\
\hline Casf1 & Mouse & CAACAGCTTTGCTAAGTGCTCTA & CACTGCTAGGGGTGGCTTTA & 60 \\
\hline $\mathrm{Il}-\mathrm{6}^{\mathrm{J}}$ & Mouse & CTGCAAGAGACTTCCATCCAGTT & GAAGTAGGGAAGGCCGTCG & 60 \\
\hline Opg & Mouse & TGCTAATTCAGAAAGGAAATGC & TGGTATAATCTTGGTAGGAACAG & 58 \\
\hline Opn & Mouse & TCTCTTGGCTGAATTCTGAGG & CTATAGGATCTGGGTGCAGGC & 60 \\
\hline Collal & Mouse & CATGTTCAGCTTTGTGGACCT & GCAGCTGACTTCAGGGATGT & 60 \\
\hline PPIA & Human & GGTATAAAAGGGGCGGGAGG & CTGCAAACAGCTCAAAGGAGAC & 60 \\
\hline HMOX1 & Human & ACTGCGTTCCTGCTCAACAT & GGGGCAGAATCTTGCACTTT & 60 \\
\hline PTHrP & Human & GTCTCAGCCGCCGCCTCAA & GGAAGAATCGTCGCCGTAAA & 60 \\
\hline$O P G$ & Human & GAAGGGCGCTACCTTGAGAT & GCA AACTGTATTTCGCTCTGG & 59 \\
\hline
\end{tabular}

Hmoxl, heme oxygenase-1 gene. 
dihydro-fluorescein diacetate, acetyl ester (CM-H2DCFDA; Invitrogen, Munich, Germany) for $1 \mathrm{~h}$ at $37^{\circ} \mathrm{C}$. Cells were washed and incubated for $15 \mathrm{~min}$ in full medium. Cells were then trypsinized and resuspended with PBS. H2DCFDA levels were measured by flow cytometry in the fluorescein isothiocyanate (FITC) channel (Attune NxT Flow Cytometer; Invitrogen, Munich, Germany) and analyzed with the FlowJo 7.6 software.

\section{Statistical analysis}

All results are shown as mean \pm standard deviation of three separate independent experiments unless stated otherwise. RT-qPCR data sets were taken as paired samples and analyzed using the repeated measures analysis of variance (ANOVA) model. For other assays, the one-way ANOVA was used. Tukey post-test was used to ascertain statistical significance among the experimental conditions with a threshold of $p<0.05(*), p<0.01(* *)$, and $p<0.001(* * *)$.

For gene expression level correlation analysis, the data were processed for outlier detection using the confidence ellipse method (1).

\section{Acknowledgments}

We are grateful to Dr. Mandy Busse for her assistance with the flow cytometry panels and handling, and to Stefanie Langwisch for her assistance with the experiments.

\section{Authors' Contributions}

Conception/design: G.G., A.C.Z., and E.V. Provision of reagents and facilities: N.N., A.C.Z., G.G., and E.V. Acquisition of data: N.A., M.S., and E.L. Analysis/interpretation of data: N.A., M.S., N.N., A.C.Z., G.G., and E.V. Writing of the article: N.A., A.C.Z., G.G., and E.V. Review of the article: N.A., N.N., J.C., E.L., G.G., A.C.Z., and E.V. Study supervision: A.C.Z., G.G., and E.V.

\section{Author Disclosure Statement}

The authors declare no potential conflicts of interest.

\section{Funding Information}

This work was supported by grants from AGENCIA-PICT 2015-1786 (Argentina), AGENCIA-PICT 2016-1366 (Argentina), UBACyT (Argentina), and the National Cancer Institute (Argentina). A.C.Z. received grants from the Deutsche Forschungsgemeinschaft (DFG, ZE 526/12-1). N.A. received a Boehringer Ingelheim Fonds travel grant.

\section{References}

1. Alexandersson A. Graphing confidence ellipses: an update of Ellip for Stata 8. Stata J Promot Commun Stat Stata 4: 242-256, 2004.

2. Almeida M. Unraveling the role of FoxOs in bone-insights from mouse models. Bone 49: 319-327, 2011.

3. Bakker AD and Klein-Nulend J. Osteoblast isolation from murine calvaria and long bones. Methods Mol Biol 816: 1929, 2012.
4. Barbagallo I, Vanella A, Peterson SJ, Kim DH, Tibullo D, Giallongo C, Vanella L, Parrinello N, Palumbo GA, Di Raimondo F, Abraham NG, and Asprinio D. Overexpression of heme oxygenase-1 increases human osteoblast stem cell differentiation. J Bone Miner Metab 28: 276-288, 2010.

5. Bonewald LF. The amazing osteocyte. J Bone Miner Res 26: 229-238, 2011.

5a. Bray F, Ferlay J, Soerjomataram I, Siegel RL, Torre LA, and Jemal A. Global cancer statistics 2018: GLOBOCAN estimates of incidence and mortality worldwide for 36 cancers in 185 countries. CA Cancer J Clin 68: 394-424, 2018.

6. Calvi LM, Sims NA, Hunzelman JL, Knight MC, Giovannetti A, Saxton JM, Kronenberg HM, Baron R, and Schipani E. Activated parathyroid hormone/parathyroid hormone-related protein receptor in osteoblastic cells differentially affects cortical and trabecular bone. J Clin Invest 107: 277-286, 2001.

7. Capulli M, Paone R, and Rucci N. Osteoblast and osteocyte: games without frontiers. Arch Biochem Biophys 561: 3-12, 2014.

8. Chen G, Sircar K, Aprikian A, Potti A, Goltzman D, and Rabbani SA. Expression of RANKL/RANK/OPG in primary and metastatic human prostate cancer as markers of disease stage and functional regulation. Cancer 107: 289298, 2006.

9. Clarke B. Normal bone anatomy and physiology. Clin J Am Soc Nephrol 3(Suppl 3): S131-S139, 2008.

10. Clines KL and Clines GA. DKK1 and Kremen expression predicts the osteoblastic response to bone metastasis. Transl Oncol 11: 873-882, 2018.

11. Damoulis PD and Hauschka PV. Nitric oxide acts in conjunction with proinflammatory cytokines to promote cell death in osteoblasts. J Bone Miner Res 12: 412-422, 1997.

12. Datta HK, Ng WF, Walker JA, Tuck SP, and Varanasi SS. The cell biology of bone metabolism. J Clin Pathol 61: 577-587, 2008.

13. Decker AM, Jung Y, Cackowski F, and Taichman RS. The role of hematopoietic stem cell niche in prostate cancer bone metastasis. J Bone Oncol 5: 117-120, 2016.

14. Downey PA and Siegel MI. Bone biology and the clinical implications for osteoporosis. Phys Ther 86: 77-91, 2006.

15. Feller L, Kramer B, and Lemmer J. A short account of metastatic bone disease. Cancer Cell Int 11: 24, 2011.

16. Ferrando M, Wan X, Meiss R, Yang J, De Siervi A, Navone $\mathrm{N}$, and Vazquez E. Heme oxygenase-1 (HO-1) expression in prostate cancer cells modulates the oxidative response in bone cells. PLoS One 8: 1-14, 2013.

17. Florczyk-Soluch U, Józefczuk E, Stẹpniewski J, Bukowska-Strakova K, Mendel M, Viscardi M, Nowak WN, Józkowicz A, and Dulak J. Various roles of heme oxygenase-1 in response of bone marrow macrophages to RANKL and in the early stage of osteoclastogenesis. Sci Rep 8: 1-15, 2018.

18. Florencio-Silva R, Rodrigues da Silva Sasso G, Sasso-Cerri E, Simões MJ, and Cerri PS. Biology of bone tissue: structure, function, and factors that influence bone cells. Biomed Res Int 2015: 421746, 2015.

19. Fournier PGJ, Dunn LK, Clines GA, and Guise TA. Tumorbone cell interactions in bone metastases. In: Heymann D 
(ed). Bone Cancer, 1st ed. Amsterdam, Netherlands: Elsevier, Inc., 2010, pp. 9-40.

20. Grochot-Przeczek A, Dulak J, and Jozkowicz A. Haem oxygenase-1: non-canonical roles in physiology and pathology. Clin Sci (Lond) 122: 93-103, 2012.

21. Gueron G, Giudice J, Valacco P, Paez A, Elguero B, Toscani M, Jaworski F, Leskow FC, Cotignola J, Marti M, Binaghi M, Navone N, and Vazquez E. Heme-oxygenase1 implications in cell morphology and the adhesive behavior of prostate cancer cells. Oncotarget 5: 4087-4102, 2014.

22. Guise TA, Mohammad KS, Clines G, Stebbins EG, Wong DH, Higgins LS, Vessella R, Corey E, Padalecki S, Suva L, and Chirgwin JM. Basic mechanisms responsible for osteolytic and osteoblastic bone metastases. Clin Cancer Res 12: 6213-6217, 2006.

23. Guise TA, Yin JJ, Taylor SD, Kumagai Y, Dallas M, Boyce BF, Yoneda T, and Mundy GR. Evidence for a causal role of parathyroid hormone-related protein in the pathogenesis of human breast cancer-mediated osteolysis. J Clin Invest 98: 1544-1549, 1996.

24. Guise TA, Yin JJ, Thomas RJ, Dallas M, Cui Y, and Gillespie MT. Parathyroid hormone-related protein (PTHrP)-(1-139) isoform is efficiently secreted in vitro and enhances breast cancer metastasis to bone in vivo. Bone 30: 670-676, 2002.

25. Han Y, You X, Xing W, Zhang Z, and Zou W. Paracrine and endocrine actions of bone-the functions of secretory proteins from osteoblasts, osteocytes, and osteoclasts. Bone Res 1: 1-11, 2018.

26. Hanai J, Chen LF, Kanno T, Ohtani-Fujita N, Kim WY, Guo WH, Imamura T, Ishidou Y, Fukuchi M, Shi MJ, Stavnezer J, Kawabata M, Miyazono K, and Ito Y. Interaction and functional cooperation of PEBP2/CBF with Smads. Synergistic induction of the immunoglobulin germline Calpha promoter. J Biol Chem 274: 31577-31582, 1999.

27. Holen I, Croucher PI, Hamdy FC, and Eaton CL. Osteoprotegerin (OPG) is a survival factor for human prostate cancer cells. Cancer Res 62: 1619-1623, 2002.

28. Holen I and Shipman CM. Role of osteoprotegerin (OPG) in cancer. Clin Sci 110: 279-291, 2006.

29. Janknecht R, Wells NJ, and Hunter T. TGF-beta-stimulated cooperation of smad proteins with the coactivators CBP/ p300. Genes Dev 12: 2114-2119, 1998.

30. Janssens K, ten Dijke P, Janssens S, and Van Hul W. Transforming growth factor-betal to the bone. Endocr Rev 26: 743-774, 2005.

31. This reference has been deleted.

32. Jin JK, Dayyani F, and Gallick GE. Steps in prostate cancer progression that lead to bone metastasis. Int J Cancer 128: 2545-2561, 2011.

33. Karsenty G, Kronenberg HM, and Settembre C. Genetic control of bone formation. Annu Rev Cell Dev Biol 25: 629-648, 2009.

34. Ke K, Safder MA, Sul OJ, Kim WK, Suh JH, Joe Y, Chung HT, and Choi HS. Hemeoxygenase-1 maintains bone mass via attenuating a redox imbalance in osteoclast. Mol Cell Endocrinol 409: 11-20, 2015.

35. Keller ET and Brown J. Prostate cancer bone metastases promote both osteolytic and osteoblastic activity. J Cell Biochem 91: 718-729, 2004.
36. Khosla S, Oursler MJ, and Monroe DG. Estrogen and the skeleton. Trends Endocrinol Metab 23: 576-581, 2012.

37. Li ZG, Yang J, Vazquez ES, Rose D, Vakar-Lopez F, Mathew P, Lopez A, Logothetis CJ, Lin S-H, and Navone NM. Low-density lipoprotein receptor-related protein 5 (LRP5) mediates the pro state cancer-induced formation of new bone. Oncogene 27: 596-603, 2008.

38. Livak KJ and Schmittgen TD. Analysis of relative gene expression data using real-time quantitative PCR and the 2(-delta delta C(T)) method. Methods 25: 402-408, 2001.

39. Loboda A, Damulewicz M, Pyza E, Jozkowicz A, and Dulak J. Role of Nrf2/HO-1 system in development, oxidative stress response and diseases: an evolutionarily conserved mechanism. Cell Mol Life Sci 73: 3221-3247, 2016.

40. Logothetis CJ, Gallick GE, Maity SN, Kim J, Aparicio A, Efstathiou E, and Lin SH. Molecular classifi cation of prostate cancer progression: foundation for marker-driven treatment of prostate cancer. Cancer Discov 3: 849-861, 2013.

41. De Marzo AM, Platz EA, Sutcliffe S, Xu J, Gronberg H, Drake CG, Nakai Y, Isaacs WB, and Nelson WG. Inflammation in prostate carcinogenesis. Nat Rev Cancer 7: 256-269, 2007.

42. Matsuo K and Irie N. Osteoclast-osteoblast communication. Arch Biochem Biophys 473: 201-209, 2008.

43. Miki T, Yano S, Hanibuchi M, Kanematsu T, Muguruma $\mathrm{H}$, and Sone S. Parathyroid hormone-related protein (PTHrP) is responsible for production of bone metastasis, but not visceral metastasis, by human small cell lung cancer SBC-5 cells in natural killer cell-depleted SCID mice. Int J Cancer 108: 511-515, 2004.

44. Mundy GR. Metastasis to bone: causes, consequences and therapeutic opportunities. Nat Rev Cancer 2: 584-593, 2002.

45. Niida A, Hiroko T, Kasai M, Furukawa Y, Nakamura Y, Suzuki Y, Sugano S, and Akiyama T. DKK1, a negative regulator of Wnt signaling, is a target of the $\beta$-catenin/TCF pathway. Oncogene 23: 8520-8526, 2004.

46. Nitti M, Piras S, Marinari U, Moretta L, Pronzato M, and Furfaro A. HO-1 induction in cancer progression: a matter of cell adaptation. Antioxidants 6: 29, 2017.

47. Nyambo R, Cross N, Lippitt J, Holen I, Bryden G, Hamdy FC, and Eaton CL. Human bone marrow stromal cells protect prostate cancer cells from TRAIL-induced apoptosis. J Bone Miner Res 19: 1712-1721, 2004.

48. Paez A, Vazquez E, and Gueron G. Heme oxygenase 1 governs the cytoskeleton at filopodia: pulling the brakes on the migratory capacity of prostate tumoral cells. Cell Death Discov 3: 17020, 2017.

49. Park JH, Lee NK, and Lee SY. Current understanding of RANK signaling in osteoclast differentiation and maturation. Mol Cells 40: 706-713, 2017.

50. Pinzone JJ, Hall BM, Thudi NK, Vonau M, Qiang YW, Rosol TJ, and Shaughnessy JD. The role of Dickkopf-1 in bone development, homeostasis, and disease. Blood 113: 517-525, 2009.

51. Pittenger MF, Mackay AM, Beck SC, Jaiswal RK, Douglas R, Mosca JD, Moorman MA, Simonetti DW, Craig S, and Marshak DR. Multilineage potential of adult human mesenchymal stem cells. Science 284: 143-147, 1999. 
52. Robling AG, Castillo AB, and Turner $\mathrm{CH}$. Biomechanical and molecular regulation of bone remodeling. Аnпи Rev Biomed Eng 8: 455-498, 2006.

53. Schilling AF, Priemel M, Timo Beil F, Haberland M, Holzmann T, Catalá-Lehnen P, Pogoda P, Blicharski D, Müldner C, Löcherbach C, Rueger JM, and Amling M. Transgenic and knock out mice in skeletal research. Towards a molecular understanding of the mammalian skeleton. J Musculoskelet Neuronal Interact 1: 27527589, 2001.

54. Suva LJ, Washam C, Nicholas RW, and Griffin RJ. Bone metastasis: mechanisms and therapeutic opportunities. Nat Rev Endocrinol 7: 208-218, 2011.

55. Szade K, Zukowska M, Szade A, Nowak W, Skulimowska I, Ciesla M, Bukowska-Strakova K, Gulati GS, Kachamakova-Trojanowska N, Kusienicka A, Einwallner E, Kijowski J, Czauderna S, Esterbauer H, Benes V, Weissman I, Dulak J, and Jozkowicz A. Heme oxygenase-1 deficiency triggers exhaustion of hematopoietic stem cells. EMBO Rep 2019. [Epub ahead of print]; DOI: 10.15252/ embr.201947895.

56. Teitelbaum SL. Osteoclasts: what do they do and how do they do it? Am J Pathol 170: 427-435, 2007.

57. Thudi NK, Martin CK, Murahari S, Shu SS, Lanigan LG, Werbeck JL, Keller ET, Mccauley LK, Pinzone JJ, and Rosol TJ. Growth and metastasis and inhibited bone. 71: 615-625, 2011.

58. Tian E, Zhan F, Walker R, Rasmussen E, Ma Y, Barlogie $\mathrm{B}$, and Shaughnessy JDJ. The role of the Wnt-signaling antagonist DKK1 in the development of osteolytic lesions in multiple myeloma. $N$ Engl J Med 349: 2483-2494, 2003.

59. Vanderschueren D, Vandenput L, Boonen S, Lindberg MK, Bouillon R, and Ohlsson C. Androgens and bone. Endocr Rev 25: 389-425, 2004.

60. Vanella L, Kim DH, Asprinio D, Peterson SJ, Barbagallo I, Vanella A, Goldstein D, Ikehara S, and Abraham NG. HO1 expression increases mesenchymal stem cell-derived osteoblast. Bone 46: 236, 2010.

61. Vanella L, Sanford C, Kim DH, Abraham NG, and Ebraheim N. Oxidative stress and heme oxygenase-1 regulated human mesenchymal stem cells differentiation. Int J Hypertens 2012: 890671, 2012.

62. Wan X, Corn PG, Yang J, Palanisamy N, Starbuck MW, Efstathiou E, Li Ning Tapia EM, Zurita AJ, Aparicio A, Ravoori MK, Vazquez ES, Robinson DR, Wu Y-M, Cao X, Iyer MK, McKeehan W, Kundra V, Wang F, Troncoso P, Chinnaiyan AM, Logothetis CJ, and Navone NM. Prostate cancer cell-stromal cell crosstalk via FGFR1 mediates antitumor activity of dovitinib in bone metastases. Sci Transl Med 6: 252ra122, 2014.

63. Wauquier F, Leotoing L, Coxam V, Guicheux J, and Wittrant Y. Oxidative stress in bone remodelling and disease. Trends Mol Med 15: 468-477, 2009.

64. Wei J, Shimazu J, Makinistoglu MP, Maurizi A, and Karsenty G. Glucose uptake and Runx2 synergize to orchestrate osteoblast differentiation and bone formation. Cell 161: 1576-1591, 2015.

65. Wong SK, Mohamad NV, Giaze TR, Chin KY, Mohamed $\mathrm{N}$, and Ima-Nirwana S. Prostate cancer and bone metastases: the underlying mechanisms. Int J Mol Sci 20, 2019.
66. Wu JB, Yin L, Shi C, Li Q, Duan P, Huang J-M, Liu C, Wang F, Lewis M, Wang Y, Lin T-P, Pan C-C, Posadas EM, Zhau HE, and Chung LWK. MAOAdependent activation of Shh-IL6-RANKL Signaling network promotes prostate cancer metastasis by engaging tumor-stromal cell interactions. Cancer Cell 31: 368-382, 2017.

67. Yang J, Fizazi K, Peleg S, Sikes CR, Raymond AK, Jamal N, Hu M, Olive M, Martinez LA, Wood CG, Logothetis CJ, Karsenty G, and Navone NM. Prostate cancer cells induce osteoblast differentiation through a Cbfa1-dependent pathway. Cancer Res 61: 5652-5659, 2001.

68. Yin JJ, Mohammad KS, Kakonen SM, Harris S, Wu-Wong JR, Wessale JL, Padley RJ, Garrett IR, Chirgwin JM, and Guise TA. A causal role for endothelin-1 in the pathogenesis of osteoblastic bone metastases. Proc Natl Acad Sci U S A 100: 10954-10959, 2003.

69. Yonou H-2004-T pdfoyuk., Ochiai A, Goya M, Kanomata N, Hokama S, Morozumi M, Sugaya K, Hatano T, and Ogawa Y. Intraosseous growth of human prostate cancer in implanted adult human bone: relationship of prostate cancer cells to osteoclasts in osteoblastic metastatic lesions. Prostate 58: 406-413, 2004.

70. Zaidi M, Inzerillo AM, Moonga BS, Bevis PJR, and Huang CL-H. Forty years of calcitonin-where are we now? A tribute to the work of Iain Macintyre, FRS. Bone 30: 655663, 2002.

71. Zwerina J, Tzima S, Hayer S, Redlich K, Hoffmann O, Henslik-Schnabel B, Smolen JS, Kollias G, and Schett G. Heme oxygenase 1 (HO-1) regulates osteoclastogenesis and bone resorption. FASEB J 19: 2011-2013, 2005.

Address correspondence to: Dr. Geraldine Gueron Departamento de Química Biológica Facultad de Ciencias Exactas y Naturales Universidad de Buenos Aires (UBA)

Instituto de Química Biológica de la Facultad de Ciencias Exactas y Naturales (IQUIBICEN) $U B A-C O N I C E T$

Intendente Guiraldes 2160 CP1428 Buenos Aires Argentina

E-mail: ggueron@gmail.com

Prof. Ana C. Zenclussen Experimental Obstetrics and Gynecology Medical Faculty

Otto-von-Guericke University Magdeburg Gerhart-Hauptmann-Str 3539108 Magdeburg Germany

E-mail: ana.zenclussen@med.ovgu.de 
Prof. Elba Vazquez

Departamento de Química Biológica Facultad de Ciencias Exactas y Naturales

Universidad de Buenos Aires (UBA)

Instituto de Química Biológica de la Facultad de Ciencias Exactas y Naturales (IQUIBICEN) $U B A-C O N I C E T$

Intendente Guiraldes 2160

CP1428 Buenos Aires

Argentina

E-mail: elba@qb.fcen.uba.ar

Date of first submission to ARS Central, September 13, 2019; date of final revised submission, December 10, 2019; date of acceptance, December 18, 2019.

\begin{aligned} \multicolumn{1}{c|}{ Abbreviations Used } \\ ANOVA $=$ analysis of variance \\ BMPs $=$ bone morphogenetic proteins \\ CDNA $=$ complementary DNA \end{aligned}

DKK1 $=$ inhibitor of $\mathrm{Wnt} / \beta$-catenin pathway in bone remodeling

$\mathrm{ES}=$ erosion surface

$\mathrm{FBS}=$ fetal bovine serum

H2DCFDA $=2^{\prime} 7^{\prime}$-dichloro dihydro-fluorescein diacetate Het $=$ heterozygous

Hmox $1=$ heme oxygenase- 1 gene

HO- $1=$ heme oxygenase- 1

$\mathrm{IL}=$ interleukin

$\mathrm{KO}=$ knockout

MSCs $=$ mesenchymal stem cells

Oc.S/BS $=$ osteoclast surface/bone surface

$\mathrm{OPG}=$ osteoprotegerin

$\mathrm{OS}=$ osteoid surface

$\mathrm{PBS}=$ phosphate-buffered saline

$\mathrm{PCa}=$ prostate cancer

$\mathrm{PCR}=$ polymerase chain reaction

PMOs $=$ primary mouse osteoblasts

$\mathrm{PTH}=$ parathyroid hormone

$\mathrm{PTHrP}=$ parathyroid hormone-related protein

$\mathrm{RANKL}=$ receptor activator for nuclear factor $\kappa \mathrm{B}$ ligand ROS $=$ reactive oxygen species

TRAP $=$ acid phosphatase tartrate resistant $\mathrm{WT}=$ wild type 